\title{
SHS-Derived Powders by Reactions' Coupling as Primary Products for Subsequent Consolidation
}

\author{
Sofiya Aydinyan ${ }^{1,2, *}$, Suren Kharatyan ${ }^{2}$ and Irina Hussainova ${ }^{1}$ (D) \\ 1 Department of Mechanical and Industrial Engineering, Tallinn University of Technology, Ehitajate 5, \\ 19180 Tallinn, Estonia; irina.hussainova@taltech.ee \\ 2 A.B. Nalbandyan Institute of Chemical Physics, National Academy of Sciences of the Republic of Armenia, \\ P. Sevak 5/2, Yerevan 0014, Armenia; suren@ichph.sci.am \\ * Correspondence: sofiya.aydinyan@taltech.ee; Tel.: +372-59-03-33-65
}

Citation: Aydinyan, S.; Kharatyan, S.; Hussainova, I. SHS-Derived Powders by Reactions' Coupling as Primary Products for Subsequent Consolidation. Materials 2021, 14, 5117. https://doi.org/10.3390/ ma14175117

Academic Editor: Damon Kent

Received: 14 July 2021

Accepted: 1 September 2021

Published: 6 September 2021

Publisher's Note: MDPI stays neutral with regard to jurisdictional claims in published maps and institutional affiliations.

Copyright: (c) 2021 by the authors. Licensee MDPI, Basel, Switzerland. This article is an open access article distributed under the terms and conditions of the Creative Commons Attribution (CC BY) license (https:// creativecommons.org/licenses/by/ $4.0 /)$.

\begin{abstract}
The capability of self-propagating high-temperature synthesis (SHS) to produce powders that are characterized by a high sintering ability, owing to high heating and cooling rates inherent to the exothermic reaction, is of a special interest for the industry. In particular, SHS-derived powders comprise a significant defect concentration in order to effectively enhance the mass transfer processes during the sintering, which allows for the successful consolidation of difficult-to-sinter materials at relatively low sintering temperatures. From this perspective, the design of precursors suitable for sintering, synthesis in a controlled temperature regime and the optimization of geometrical and structural parameters of SHS powders as a potential feedstock for the consolidation is of key importance. Here, we report on the comparative studies concerning the SHS processing of composites for advanced powder metallurgy techniques. The synthesis and sintering peculiarities of the SHS through coupled reactions in the $\mathrm{Me}^{\prime} \mathrm{O}_{3}\left(\mathrm{WO}_{3}, \mathrm{MoO}_{3}\right)-\mathrm{Me}{ }^{\prime \prime} \mathrm{O}(\mathrm{CuO}, \mathrm{NiO})-\mathrm{Mg}-\mathrm{C}, \mathrm{Ti}-\mathrm{B}-\mathrm{Al}_{12} \mathrm{Mg}_{17}$ systems are comparatively reviewed. The SHS coupling approach was used for the preparation of powders with a tuned degree of fineness (a high specific surface area of particles), a high-homogeneity and a controllable distribution of elements via both the regulation of the thermal regime of combustion in a wide range and the matching of the thermal and kinetic requirements of two interconnected reactions. Microstructural features of the powder feedstock greatly contributed to the subsequent consolidation process.
\end{abstract}

Keywords: self-propagating high-temperature synthesis; combustion synthesized powder; thermal coupling; sintering; microstructure; mechanical properties

\section{Introduction}

Self-propagating high-temperature synthesis (SHS) or combustion synthesis (CS) is an exothermic chemical reaction that proceeds in a self-sustaining mode, leading to the formation of valuable solid products. Once initiated by means of a local thermal source, a highly exothermic chemical reaction self-propagates through the heterogeneous medium, converting precursors into products within short reaction times (in the order of seconds or minutes) [1-3]. SHS processes are used to synthesize advanced materials, including intermetallics, alloys, pseudoalloys and metal matrix composites, as well as pure metals and refractory ceramics using just high-caloric reacting mixtures, which enable the generation of a sufficient amount of energy. SHS provides a wide range of materials in the form of powders, porous materials, non-porous compacts, casts and coatings. In comparison with the conventional methods of synthesizing materials in high-temperature furnaces, SHS has a number of obvious advantages, namely: a low energy consumption, simple and small-sized equipment, a high productivity and effectiveness, environmental safety, scaling-up ability and the high purity of products due to a self-purification phenomenon at high temperatures. These attractive features endow SHS with a great flexibility, allowing it to both manufacture a wide diversity of products using essentially the same equipment, 
and establish a number of productions based on them [3]. The most important families of engineering ceramics (metal borides, carbides and nitrides) have also been successfully produced via SHS, both from the elements and from naturally available precursors. Further studies demonstrated the capability of the SHS technique to produce powders that are characterized by a high sintering capacity with respect to powders produced by traditional techniques (furnace, solution methods, etc.) [4,5]. The improved sinterability of SHS powders is attributed to the significant concentration of inborn defects, owing to extremely high heating and cooling processes imminent in the exothermic reaction [5-8]. These defects are importantly entertained in various physicochemical phenomena, particularly at elevated temperatures. The high concentration of defects in the SHS-derived powders is regarded as being likely to both intensify the mass transfer processes during sintering and allow for the successful consolidation of refractory materials at relatively low sintering temperatures $[5,6]$.

Hence, for a wider application of the SHS method, an innovative direction is developing: the design, synthesis and optimization of SHS powders as a potential feedstock for consolidation via advanced methods, such as additive manufacturing (AM), spark plasma sintering (SPS), hot explosive compaction (HEC), etc.

Spark plasma sintering (SPS) enables the preservation of the microstructural features originated in the combustion wave [9]. It is transpired as an advanced and extraordinary consolidation method to sinter a wide variety of materials that are effortful to sinter by conventional hot pressing techniques. In the SPS, the densification is performed by the application of a pulsed electric field, supplemented with resistance heating and pressure. Recently, the superiority of consolidating materials of a high density in a rather short time and a lower temperature, as compared to conventional sintering techniques, was manifested by the hot explosive consolidation (HEC) method $[10,11]$. The explosive compaction process of powders is a cost-effective fabrication procedure that is based on the shock wave propagation produced from the detonation of explosives. The shock wave passes through a thin wall of the cylindrical steel container to the powder and consolidates the material due to an induced high pressure. HEC is presumed to be applicable to the fabrication of high-density coupons from SHS-derived ultrafine structured composites.

AM or 3D printing through the selective laser melting (SLM) of metals and selective laser sintering (SLS) of ceramic powders without polymer binders has intrigued the research community, opening a new era of generating the cost-effective and low-waste production of complex shaped, precisely dimensioned and high-value parts $[12,13]$. The design and development of the advanced SHS technology for AM powders (metals, alloys, ceramics and composites) allow to minimize the manufacturing time and waste of materials and energy, and to facilitate the fabrication of complex parts. The progress of combining SHS and advanced consolidation technologies opens a prospective avenue for the fast, cost-efficient and large-scale production of required powdered materials with a designed architecture. In this regard, SHS-prepared ceramic and composite materials obtained by coupled reactions and compacted by different advanced sintering techniques (HEC, SPS and SLM) are comparatively analyzed below. Here, we report on the design of the SHS route for producing precursors of a controllable microstructure, composition and high purity that are suitable for SPS, HEC or SLM/SLS, which may expand the possibility of SHS to synthesize materials in a controlled temperature regime. From this prospective, the approaches of reactions' coupling, thermal dilution and mechanical activation become promising [14-16]. The reactions' coupling fuels opportunities for the creation of new energy-efficient processes and broadens the scope of materials that can be synthesized by SHS via the matching of the thermal and kinetic requirements of two interconnected reactions $[17,18]$. Distinguished advantages of the reactions' coupling approach in combustion synthesis are (i) the intensification of high exothermic solid-state reactions with strong diffusion retardation or low exothermic reactions; (ii) the enhancement of the concentration limits of combustion; and (iii) the creation of methodologies/strategies that facilitate the design of materials with a required micro(nano)structure and relevant properties, due to 
the regulation of the thermal regime of combustion in a wide range. The latter aspect is of primary importance for the subsequent consolidation procedure.

SHS processes use only high-caloric reacting mixtures, enabling to generate a sufficient amount of energy, or often, despite being highly exothermic reactions, they cannot proceed in a self-sustaining manner, owing to strong diffusion retardation. On the other hand, reactions with a very high thermal effect are also not suitable for the materials' synthesis, since they proceed too violently, in a non-controllable explosion mode that leads to the non-complete conversion of reagents, evaporation of precursors and intermediates, agglomeration, etc.

The design of new systems by coupling a low exothermic reaction with a high exothermic one contributes to the temperature-controlled self-sustaining process and to the preparation of suitable powder precursors for the fabrication of counter-bodies. The effective control over the thermal regime of the process enhances the degree of conversion and homogeneity of the combustion product [19-22].

Another possibility in designing and fabricating novel materials for advanced consolidation with tailored physical-mechanical properties is solution combustion synthesis (SCS) [23], a self-sustained exothermic reaction that takes place in a mixture or homogeneous solution of precursors. Intensive gas evolution during the solution combustion reaction prevents agglomeration and the grain growth of the product at a high reaction temperature. Therewith, the high reaction temperatures will favor the formation of a highly crystalline nanostructure that is beneficial for the sintering processes.

The synthesis and sintering peculiarities of the following SHS-derived composite powders are comparatively reviewed. Among the powders, there are tungsten-copper (HEC), tungsten-nickel (SPS), molybdenum-copper (SPS, SLM) and titanium diboride- $\mathrm{AlMgB}_{14}$ (SPS). The preparation of the aforementioned powder feedstock with the tuned degree of fineness (a high specific surface area of particles) of a high-homogeneity and controllable distribution, specific microstructural features and the partial merging of particles by SHS provides a beneficial ground for the successful sintering/densification process and fabrication of bulk samples with enhanced physicomechanical properties.

\section{The Role of Coupling on the Synthesis and Sintering of SHS Powders}

For the implementation of the synthesis of advanced materials in the combustion wave and design of their microstructure, the cause-and-effect relationship between the composition of the reactive mixture-combustion wave structure, propagation velocityphase composition and microstructure of products is substantial. Great opportunities are offered by the reactions' coupling approach.

Through the utilization of the coupling approach, the macrokinetic and microkinetic aspects of controlling basic characteristics of the SHS wave-temperature profile, thermal gradients and propagating velocity are tuned in order to obtain the target products of a high purity and desired microstructure.

\subsection{The Combustion Synthesis by Coupling Approach and Sintering of the $M e^{\prime}-M e^{\prime \prime}$ Composite Powders}

The synthesis and sintering peculiarities of tungsten-copper (HEC), tungsten-nickel (SPS), molybdenum-copper (SPS, SLM) and titanium diboride-AlMgB $\mathrm{Al}_{14}$ (SPS) systems are delivered below.

For the preparation of $\mathrm{W}-\mathrm{Cu}, \mathrm{W}-\mathrm{Ni}$ and $\mathrm{Mo}-\mathrm{Cu}$ composite nanomaterials, the joint magnesio- and carbothermic reduction (using a combined $\mathrm{Mg}+\mathrm{C}$ reducer) of their corresponding oxides $\left(\mathrm{WO}_{3}, \mathrm{CuO}, \mathrm{NiO}\right.$ and $\left.\mathrm{MoO}_{3}\right)$ was successfully designed and accomplished in a guided combustion mode (referred to as a reactions' thermo-chemical coupling). The use of a $\mathrm{Mg}+\mathrm{C}$ reducing mixture considers the regulation of the combustion temperature and velocity within a certain range and the implementation of the synthesis in controllable conditions.

Before the combustion experiments, the thermodynamic calculations (TC) were performed in the quaternary systems in order to synthesize $\mathrm{Cu}$ and Ni-refractory metal alloys 
with 1:1 proportions of metals (Figure 1). The thermodynamic modeling of the quaternary $\mathrm{Me}^{\prime} \mathrm{O}_{3}\left(\mathrm{WO}_{3}, \mathrm{MoO}_{3}\right)-\mathrm{Me}^{\prime \prime} \mathrm{O}(\mathrm{CuO}, \mathrm{NiO})-\mathrm{Mg}-\mathrm{C}$ systems showed that the interactions are not a simple summation of corresponding $\mathrm{Me}^{\prime} \mathrm{O}_{3}-\mathrm{Me}{ }^{\prime \prime} \mathrm{O}-\mathrm{Mg} \& \mathrm{Me}^{\prime} \mathrm{O}_{3}-\mathrm{Me}^{\prime \prime} \mathrm{O}-\mathrm{C}$ ternary systems. The formation areas and corresponding adiabatic temperatures for $\mathrm{Mo}-\mathrm{Cu}, \mathrm{W}-\mathrm{Ni}$ and $\mathrm{W}-\mathrm{Cu}$ bimetallic systems were calculated depending on the reducers' amounts (carbon $(\mathrm{x})$ and magnesium (y)). The adiabatic combustion temperature and equilibrium composition of products were deduced and optimized according to the ambient gas pressure. Thermodynamic modeling ensured the use of $\geq 0.3 \mathrm{MPa}$ ambient gas pressure in order to avoid the evaporation of precursors and intermediates, their mechanical scattering and vigorous gas emissions.

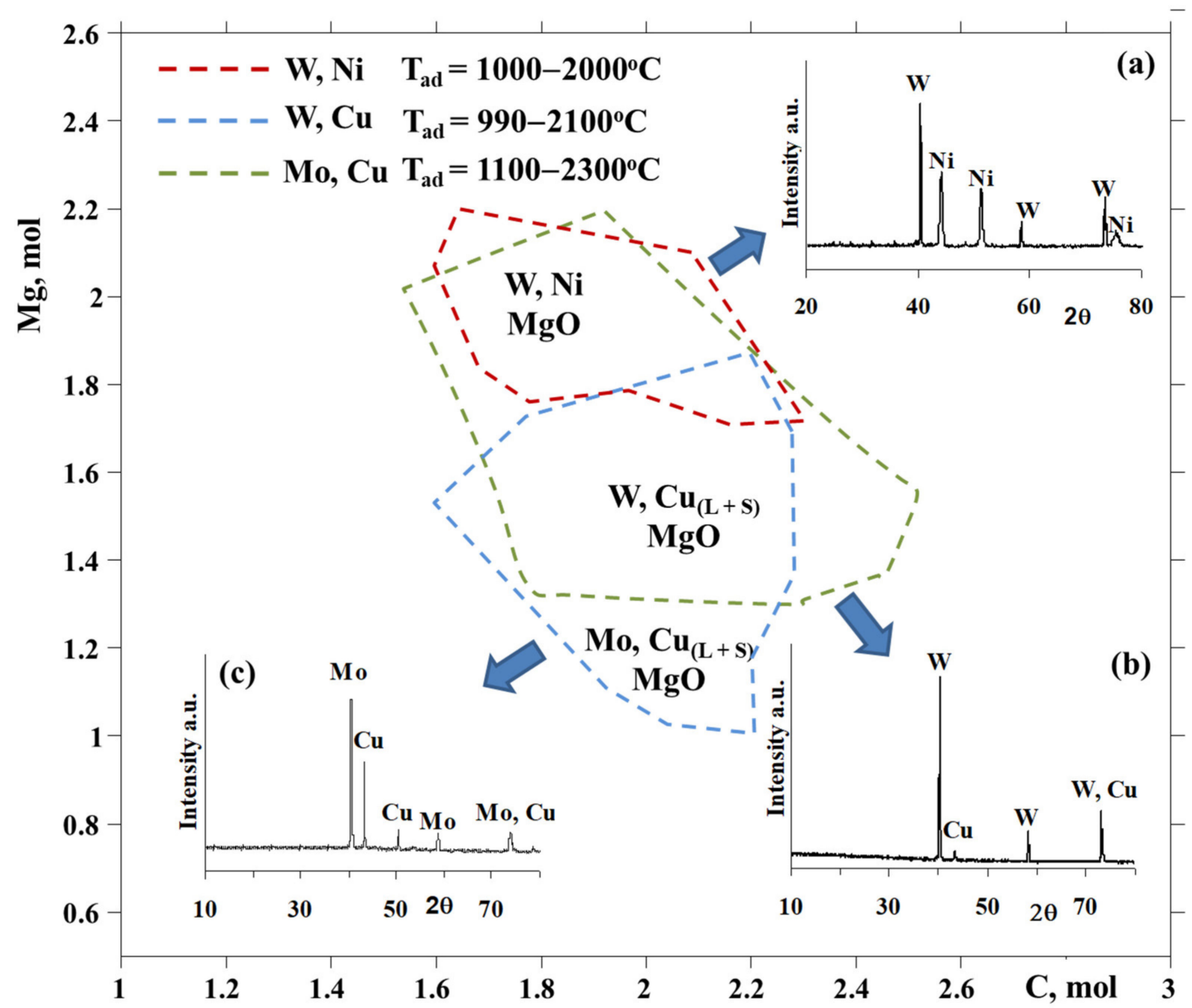

Figure 1. Thermodynamic modelling of $\mathrm{WO}_{3}-\mathrm{CuO}-\mathrm{yMg}-\mathrm{xC}, \mathrm{WO}_{3}-\mathrm{NiO}-\mathrm{yMg}-\mathrm{xC}$ and $\mathrm{MoO}_{3}-\mathrm{CuO}-\mathrm{yMg}-\mathrm{xC}$ systems and $\mathrm{XRD}$ patterns of the products ( $\mathrm{W}-\mathrm{Ni}(\mathrm{a}), \mathrm{W}-\mathrm{Cu}(\mathrm{b})$ and $\mathrm{Mo}-\mathrm{Cu}(\mathrm{c})$ ) at optimum conditions, $\mathrm{P}=0.3 \mathrm{MPa}$.

\subsection{The Essence of Reactions' Thermal-Kinetic Coupling Approach}

The role of coupling on the nature of combustion thermograms is demonstrated on the example of the $\mathrm{MoO}_{3}-\mathrm{CuO}-\mathrm{Mg}-\mathrm{C}$ system. The combustion process in the $\left(\mathrm{MoO}_{3}-\mathrm{CuO}\right)(\mathrm{A})$ $+\mathrm{Mg}(\mathrm{B})$ mixture proceeds in an explosion mode (Figure $2 \mathrm{a}$ ), and the pure carbothermic reaction $\left(\mathrm{MoO}_{3}-\mathrm{CuO}\right)(\mathrm{A})+\mathrm{C}(\mathrm{D})$ does not have enough exothermicity to self-propagate (Figure 2c), whereas the introduction of carbon to the $\mathrm{MoO}_{3}-\mathrm{CuO}-\mathrm{Mg}$ mixture reduces combustion parameters and allows to perform the combustion process at a moderate combustion regime $(\mathrm{A}+\mathrm{B}+\mathrm{D})$ [24]. Therefore, the addition of carbon has a disproportionate 
influence on the combustion velocity and temperature, and thereby on the microstructure and phase composition of the products. In particular, the addition of a small amount of carbon (up to $0.7 \mathrm{wt} \%$ ) to the $\mathrm{MoO}_{3}+\mathrm{CuO}+\mathrm{Mg}$ green mixture causes a decrease in combustion velocity of more than 10-fold (Figures 2a and 3). At that velocity, the combustion temperature decreases by only $300^{\circ} \mathrm{C}$ (Figure 3). Note that, in parallel, a sharp decline of the heating rate of the reagents also occur (by one order in the $\mathrm{CuO}-\mathrm{MoO}_{3}-\mathrm{Mg}-\mathrm{C}$ system) and a double-stage nature of the combustion wave appears on the combustion thermogram (Figures $2 \mathrm{~b}$ and 3 ).

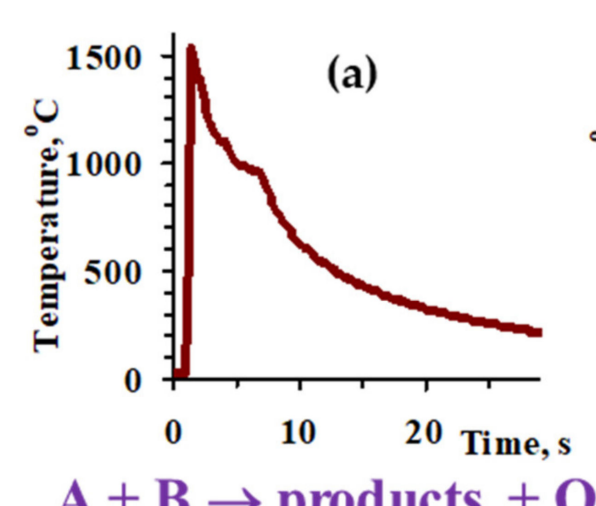

$$
\mathrm{A}+\mathrm{B} \rightarrow \text { products }+\mathrm{Q}_{1}
$$
(explosion)
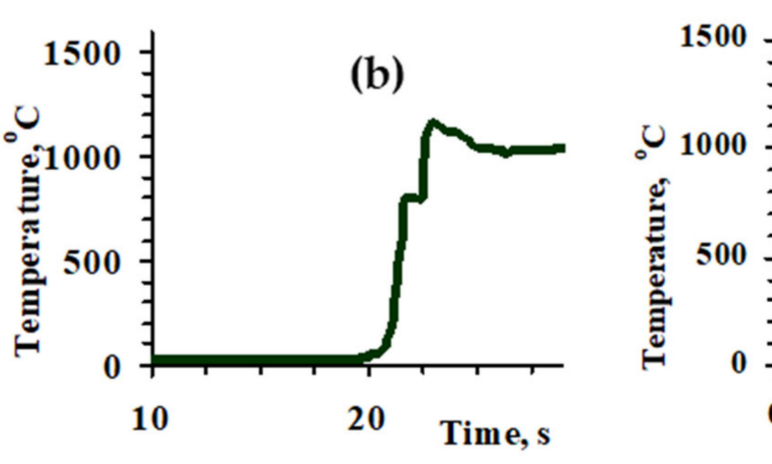

$$
\mathbf{A}+\mathbf{B}+\mathbf{D} \rightarrow \text { products }+\mathbf{Q}_{2}
$$
(moderate thermal mode) (c)

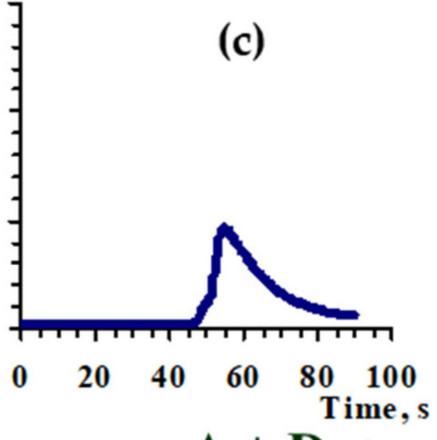

$\mathbf{A}+\mathbf{D} \neq$ no reaction

Figure 2. Combustion temperature profiles of the $\mathrm{CuO}+\mathrm{MoO}_{3}+1.2 \mathrm{Mg}+\mathrm{xC}$ mixtures, $\mathrm{x}=0(\mathbf{a}), \mathrm{x}=5.0(\mathbf{b}), \mathrm{CuO}+\mathrm{MoO}+$ $\mathrm{C}$ (c) $\left(\mathrm{Q}_{1}\right.$ and $\mathrm{Q}_{2}$ are the amount of heat released). $\mathrm{P}_{\mathrm{N} 2}=0.3 \mathrm{MPa}$.

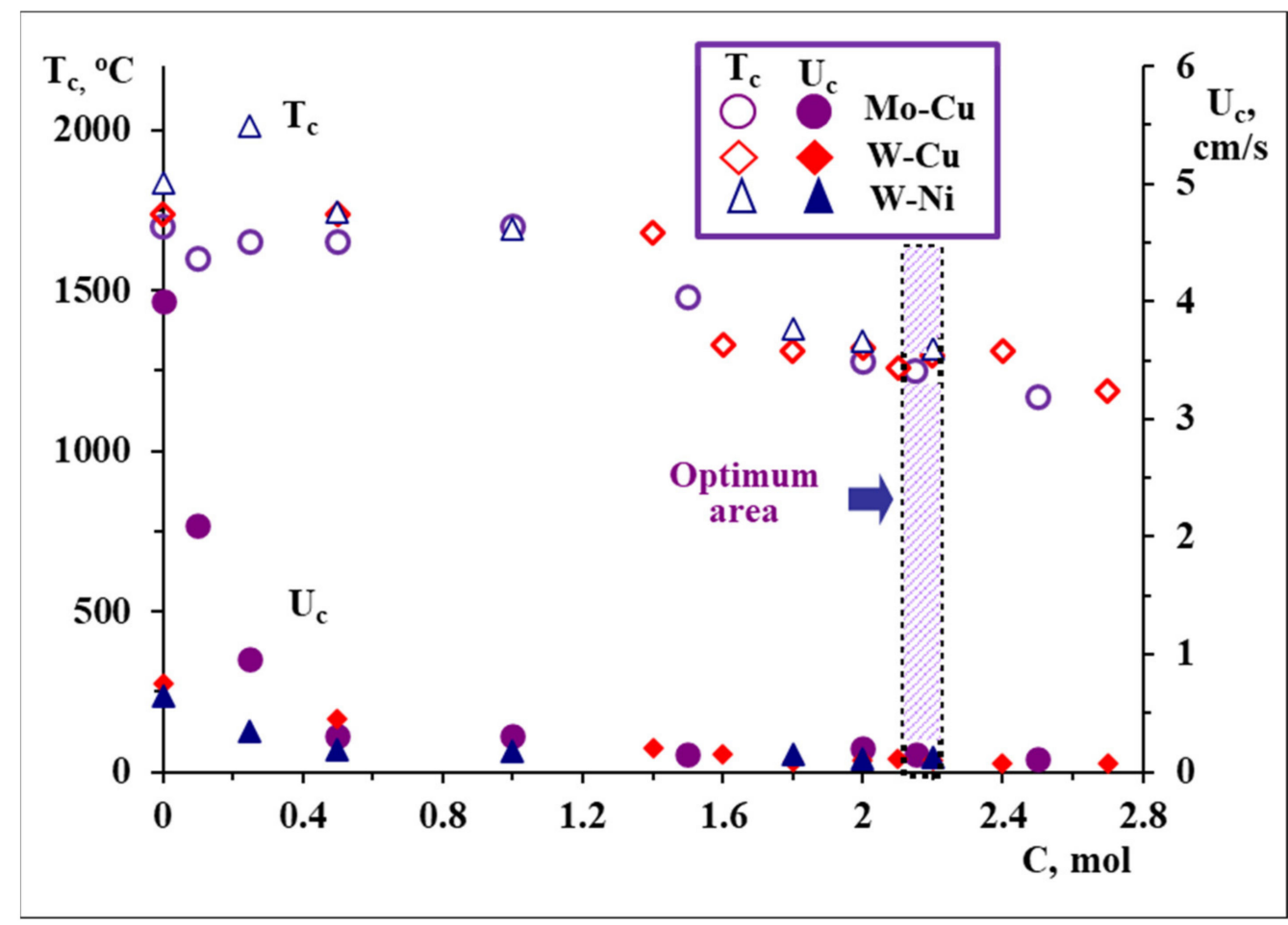

Figure 3. Combustion temperature $\left(\mathrm{T}_{\mathrm{c}}\right)$ and combustion velocity $\left(\mathrm{U}_{\mathrm{c}}\right)$ vs. carbon content in the $\mathrm{WO}_{3}-\mathrm{CuO}-1.3 \mathrm{Mg}-\mathrm{xC}, \mathrm{WO}_{3}-\mathrm{NiO}-1.7 \mathrm{Mg}-\mathrm{xC}$ and $\mathrm{MoO}_{3}-\mathrm{CuO}-1.2 \mathrm{Mg}-\mathrm{xC}$ systems. $\mathrm{P}=0.3 \mathrm{MPa}$.

According to the XRD analysis of the combustion products, the role of carbon is essential for controlling the reduction degree of metals. For instance, the $\mathrm{MoO}_{3}+\mathrm{CuO}$ $+1.2 \mathrm{Mg}+2.2 \mathrm{C}$ composition was found to be optimum for the preparation of the Mo-Cu 
composite powder (Figure 1c). The coupling of the reactions has a substantial effect on the microstructural characteristics of obtained composite materials; for instance, when increasing the amount of carbon (from 1.4 up to $2.1 \mathrm{~mol}$ ), a 5-fold decrease in the grain size of the combustion product was observed due to a significant reduction in the combustion temperature [24].

Thus, the role of reactions' coupling is evident from the phase composition and microstructure features, and from the transformation of combustion thermograms (Figure 2a,b). When carbon is added, the reaction mechanism drastically changes; in particular, the singlestage interaction turns into a double-stage, which establishes favorable conditions for the preparation of target products at a moderate thermal mode.

\subsubsection{Copper-Tungsten Bimetallic System}

Copper (II) oxide (High grade, STANCHEM, Poland, $<40 \mu \mathrm{m}$ ), tungsten (VI) (High grade, Krasniy khimik, Ukraine, $<40 \mu \mathrm{m}$ ) oxide, carbon black (P-803, Russia, $<1 \mu \mathrm{m}$ ) and magnesium (MPF-3, Russia, 150-300 $\mu \mathrm{m}$ ) were used to prepare $\mathrm{Cu}-\mathrm{W}$ powders in combustion experiments. Cylindrical samples were fabricated from the initial mixture of the reactants via uniaxial pressing $(\mathrm{P}=1 \mathrm{kN})$ and placed in a constant pressure reactor (CPR-3l reaction chamber). The reactor was filled with nitrogen (purity $99.97 \%$ ) to a pressure of up to 3.0 MPa. The combustion reaction was initiated by a short-term annealing of a tungsten coil. Temperature-time histories of the combustion process were recorded by W-Re thermocouples (5Re/20Re). The preparation of samples for the typical combustion experiment and registration of combustion parameters is thoroughly described elsewhere $[1,3,10]$. A preliminary thermodynamic consideration of the $\mathrm{WO}_{3}-\mathrm{CuO}-\mathrm{yMg}-\mathrm{xC}$ system showed that $\mathrm{Cu}: \mathrm{W}$ of 1:1 composition can be synthesized due to the variation of the amount of $\mathrm{Mg}$ between 1.3 and $2.2 \mathrm{~mol}$ at a change in carbon amount in the range of 1.5 to $2.5 \mathrm{~mol}$ (Figure 1).

The combustion reaction was implemented at a gas pressure of $\mathrm{P}=0.3 \mathrm{MPa}$ in order to avoid the evaporation of various $\mathrm{WO}_{\mathrm{x}}$ oxides, magnesium and copper. According to thermodynamic modelling, the combined magnesio-carbothermic reduction of copper and tungsten oxides was performed in the $\mathrm{WO}_{3}-\mathrm{CuO}-\mathrm{yMg}-\mathrm{xC}$ system at a fixed amount of $\mathrm{Mg}(\mathrm{y}=1.3 \mathrm{~mol})$ and various amounts of the carbon reducer. Thermodynamic data were rather supported by experiments and indicated the reasonable choice of reducers' amounts in order to provide a complete and joint reduction of metals at moderate temperatures (Figure 3) [10].

A number of SHS experiments were performed, with the aim to explore the overall (qualitative and quantitative) impact of carbon on the peculiarities of self-sustained reaction, morphology evolution and phase formation patterns. It was revealed that the decrease in combustion temperature and velocity versus the increase in carbon amount was observed as a result of the increased fraction of low-exothermic carbothermic process (Figure 3).

XRD examinations of the solid combustion products for the $\mathrm{WO}_{3}+\mathrm{CuO}+1.3 \mathrm{Mg}+\mathrm{xC}$ mixtures indicated that a carbon amount of 2.1-2.2 mol makes it possible to produce target compounds of combustion (Figure $1 \mathrm{~b}$ ), i.e., $\mathrm{W}-\mathrm{Cu}$ and its by-product, $\mathrm{MgO}$, which was leached by $10 \mathrm{wt} \%$ hydrochloric acid. The preparation of the $\mathrm{W}-\mathrm{Cu}=1: 1$ alloy becomes feasible at $T_{\mathrm{C}}=1150-1300{ }^{\circ} \mathrm{C}$, which is close to the optimum and low-temperature area of thermodynamic prediction.

Microstructural examinations combined with XRD analysis demonstrated the presence of fine and snowflake-like particles of the $\mathrm{W}-\mathrm{Cu}$ alloy in the submicron range and with $\sim 1.4 \mathrm{~m}^{2} \cdot \mathrm{g}^{-1}$ SSA (specific surface area) after the acid leaching of the combustion products (Figure 4a). The partial merging of the particulates (up to tenths of microns) in the combustion wave was observed due to a higher combustion temperature than the melting point of copper (Figure $4 \mathrm{~b}$ ). The presence of such agglomerates gives a predisposition for subsequent consolidation via promoting the emergence of intimate bindings among grains and boundaries, thereby reducing diffusion distances and significantly facilitating the sintering of SHS powders. 

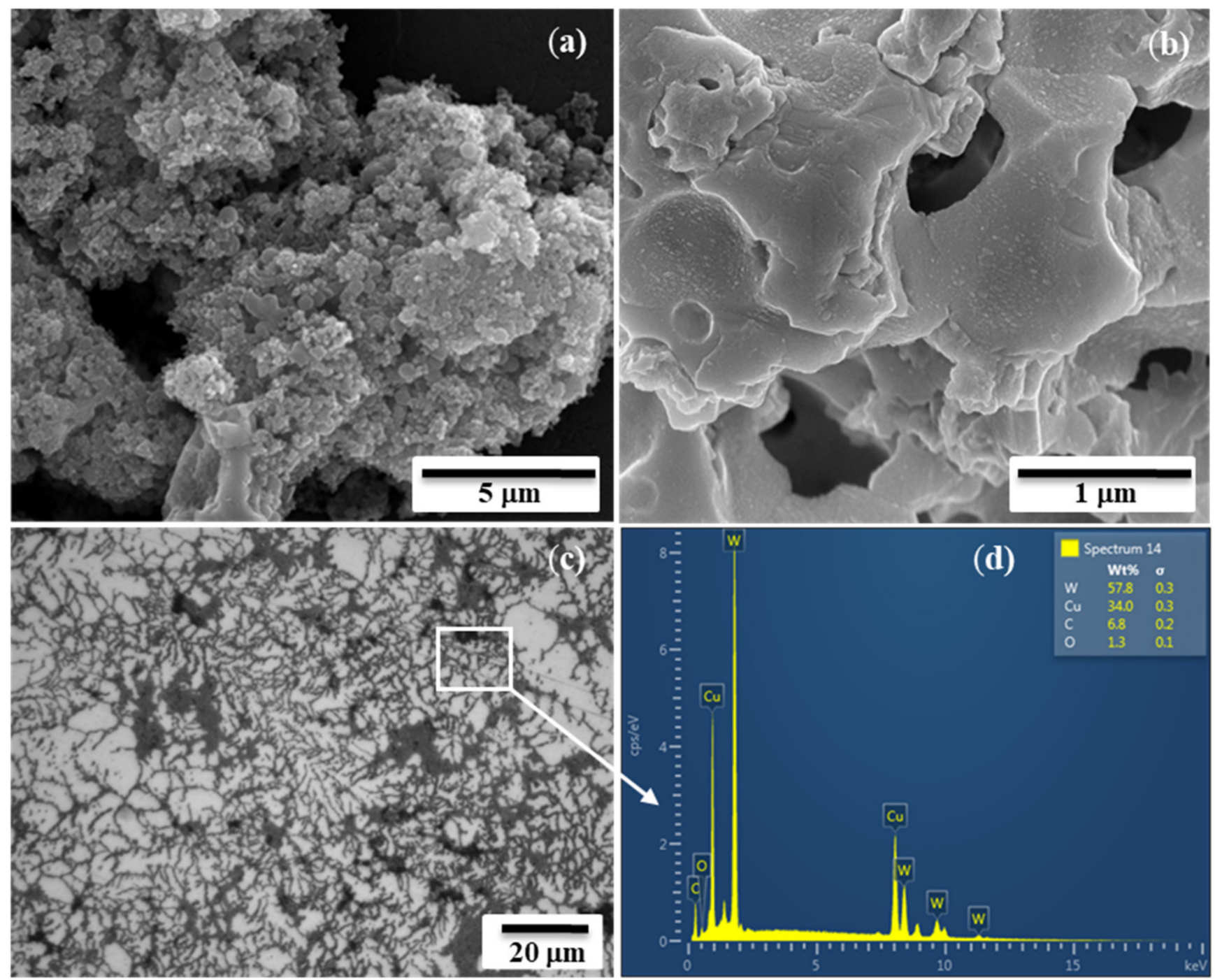

Figure 4. SEM images of SHS-derived W-Cu powder $(\mathbf{a}, \mathbf{b})$ and SEM/EDS of fracture surface of HEC counterparts (c,d).

The fabrication of $\mathrm{W}-\mathrm{Cu}$ green parts of a high relative density from the combustion synthesized powders was performed via the hot explosive consolidation (HEC) method. For the HEC procedure, the SHS-derived tungsten-copper composite powder was poured into a cylindrical tube container made of steel and pre-densified with a static pressure of $1.5 \mathrm{t}$ load. The compacts of powdered samples were processed by the dynamic predensification of coupons at a room temperature and a hot explosive consolidation from 700 to $1050{ }^{\circ} \mathrm{C}$ (approximately 10 to $20 \mathrm{~K} \cdot \mathrm{s}^{-1}$ within 0.3 to $1 \mathrm{~min}$ ).

Cylindrical steel tubes of various dimensions were utilized to optimize the consolidation of $\mathrm{W}-\mathrm{Cu}$ alloys at certain conditions of the detonation pressure, temperature and initial density. Optimized parameters were identified according to pre-densification at room temperature, firstly applying static pressure via compression at different intensities $(1.5 \mathrm{t})$, and then explosive densification at 950,1000 and $1050{ }^{\circ} \mathrm{C}$, with a loading intensity of $10 \mathrm{GPa}[10,11]$.

HEC-prepared billets from fine SHS-derived powders exhibited a severe diamagnetic susceptibility response. In addition, the microhardness and density measurements manifested that W-Cu alloys obtained by the SHS method via the coupling approach and subsequently compacted by explosive technology comprise an approximately twofold increased microhardness, as compared to those obtained by mechanical alloying $\left(370 \mathrm{~kg} \cdot \mathrm{mm}^{-2} \mathrm{vs}\right.$ $200 \mathrm{~kg} \cdot \mathrm{mm}^{-2}$ ), and have a relative density near to the theoretical value (according to both the geometrical and Archimedes values). 
The SEM analysis results indicated that $1000^{\circ} \mathrm{C}$ is considered an optimum temperature for the complete annealing of microscopic defects and internal stresses from the $\mathrm{W}-\mathrm{Cu}$ alloys. The optimum annealing temperature was also found to be $1000{ }^{\circ} \mathrm{C}$, according to both the internal friction and Young modulus (E) values. However, they depend not only on the annealing conditions, but also on the history of the sample; in particular, the conditions of powder synthesis, post-treatment, distribution of dendrites, etc.

Microstructural and spectral analyses indicated a homogeneous structure of the obtained W-Cu composites (dark gray corresponds to copper, and light gray corresponds to tungsten) (Figure 4c,d). According to those examinations, the surface of the compacted specimens was almost free of cracks and visible defects. Dendrite formation in $\mathrm{W}-\mathrm{Cu}$ composite materials is conditioned by the distinct differences in the metals' melting points, crystal structure and insolubility in each other. The supercooling of the material after HEC and the anisotropy in the surface energy of the tungsten-copper interface led the solid nucleus of tungsten-rich particles to grow in the under-sintered pool of copper in preferred growth directions of the tungsten. Such a highly textured dendrite microstructure of micron-size- $W$ rich dendrites may provide a greater freedom of expansion and contraction (plasticity) when exposed to high thermal loads, suggesting them as the potential candidates for high temperature coatings. On the contrary, the utilization of mechanically alloyed commercial powders for shock wave consolidation has not allowed for the achievement of dense samples (<95\%) [25]. High-velocity wave propagation extrudes copper from the adjacent areas of $\mathrm{W}$ particles; they instantaneously impact each other and aggregate, creating both pores and the inhomogeneous distribution of constituents.

\subsubsection{Nickel-Tungsten Bimetallic System}

Nickel (II) oxide (Alfa Aesar, $>99 \%,<44 \mu \mathrm{m}$ ), tungsten (VI) oxide (High grade, Krasniy khimik, Ukraine, $<40 \mu \mathrm{m}$ ), carbon black (P-803, Russia, $<1 \mu \mathrm{m}$ ) and magnesium (MPF-3, Russia, $150-300 \mu \mathrm{m}$ ) were used to prepare Ni-W powders in combustion experiments. Thermodynamic calculations in the $\mathrm{NiO}-\mathrm{WO}_{3}-\mathrm{yMg}-\mathrm{xC}$ system demonstrated that the formation of a target product (Ni:W = 1:1 molar ratio) is achievable in a certain amount of carbon (from 1.6 to $2.3 \mathrm{~mol}$ ) and magnesium (from 1.7 to $2.2 \mathrm{~mol}$ ) at a $1000-2000{ }^{\circ} \mathrm{C}$ adiabatic temperature interval, allowing to design the optimum synthesis circumstances for the simultaneous and entire reduction of tungsten and nickel oxides in a wide range of compositions and thermal conditions (Figure 1) [26]. The probable formation of tungsten carbides (WC and $\mathrm{W}_{2} \mathrm{C}$ ) was ruled out during the thermodynamic calculations. According to the results of TC, the amount of magnesium selected was around 1.7-1.8 mol, in order to be sufficient to implement the self-sustaining reaction and provide the complete reduction of oxides at comparatively lower temperatures at a certain amount of carbon. By the next step, the influence of the carbon quantity on the combustion parameters and products' characteristics was revealed, with the aim to find out the optimum composition of the $\mathrm{NiO}$ $+\mathrm{WO}_{3}+\mathrm{yMg}+\mathrm{xC}$ mixture in order to produce the W-Ni alloy (Figure 3). By the same token, the magnesio-carbothermic combined reduction of $\mathrm{WO}_{3}$ and $\mathrm{NiO}$ was performed via changing the amount of carbon within a prescribed range, in accordance with the TC predicted area. It was revealed that the increase in the carbon amount is responsible for the reduction in the combustion parameters (temperature and velocity), conditioned by a consistent increase in the contribution of the low-caloric carbothermic reaction in the system in one hand, and the change in the interaction mechanism in another [26]. Specifically, at a low amount of carbon, molten $\mathrm{NiO}$ participates in the process, and at a high carbon content, solid $\mathrm{NiO}$ participates in the process. The investigation of the interaction mechanism in the current mixture revealed that, in contrast to the $\mathrm{CuO}-\mathrm{WO}_{3}-\mathrm{Mg}-\mathrm{C}$ system, the interaction is initiated with the magnesiothermic reduction of $\mathrm{NiO}$, which is decisive for the heat release and self-propagation of the combustion wave. The reduction process is then continued with the magnesio-carbothermic reduction of $\mathrm{WO}_{3}$, and accompanied by the Ni-rich phase $\left(\mathrm{Ni}_{17} \mathrm{~W}_{3}\right.$ or $\left.\mathrm{Ni}_{4} \mathrm{~W}\right)$ formation. An unconsumed amount of oxides reduce up to the metals due to the carbothermic process. In addition, the combustion temperature in the system 
under consideration is comparatively lower (even lower than the melting temperature of nickel (fusible metal)), and at that temperature, the reduced metallic components are in a solid state and are of more homogeneity as compared to bimetallic systems with molten ingredients. Here, nickel and tungsten form nickel and/or tungsten-rich solid solutions or nickel-rich intermetallic with a particular ratio of elements $\left(\mathrm{Ni}_{17} \mathrm{~W}_{3}\right.$ or $\left.\mathrm{Ni}_{4} \mathrm{~W}\right)$, along with the tungsten-rich phase corresponding to the W-Ni composition (1:1 molar ratio) (Figure 1a).

Based on the XRD patterns of the products, the optimum conditions, according to the initial mixture composition and inert gas pressure, were determined for the preparation of the $\mathrm{W}-\mathrm{Ni}$ bimetallic system. It was revealed that the conversion degree tends to increase when increasing the amount of carbon in the reactive mixture. The XRD showed that the reduction degree increases with an increase in carbon amount;), the optimum area of the target alloy preparation according to the carbon amount $(x=2.2-3 \mathrm{~mol})$ was also determined. The absence of peaks of metallic nickel and nickel oxide from XRD patterns, as well as the absence of magnetic properties, confirm the formation of the W-Ni bimetallic system. Note that two different combustion modes were observed, according to the carbon amount in the $\mathrm{NiO}-\mathrm{WO}_{3}-\mathrm{yMg}-\mathrm{xC}$ system: a steady state (with a carbon amount of around $2.2 \mathrm{~mol}$ ) and an unsteady mode at a high-carbon content $(5 \mathrm{~mol})$. The latter corresponds to the spin combustion mode, demonstrating a change in both the microstructure and phase composition of the products [26].

The target SHS product was crushed into a powder after cooling and hydrochloric acid leaching was used to eliminate byproduct magnesia. XRD and SEM/EDS examinations showed that the product after acid treatment contained mainly Ni and W elements, with an average particle size in the submicron range (Figure 5a,b), illustrating the homogeneous dispersion of both metals throughout the sample. It is obvious that the characteristic peaks of tungsten are broadened and correspond to the $\mathrm{W}-\mathrm{Ni}$ solid solution, and that the nickel peaks are right-shifted and broadened (Ni-W solid solution).

Emphasizing the influence of reactions' coupling on the microstructure features, one may observe the fine microstructure formation during the addition of carbon, accompanied with a simultaneous decline in combustion temperature and velocity, and, as a result, the fabrication of the W-Ni bimetallic system at moderate and tailored conditions.

SHS-derived powders were ball milled for 30-60 min at a fixed rotation speed of $200 \mathrm{rpm}$ at a ball-to-powder weight ratio of 4:1, and were subsequently compacted by a spark plasma sintering (SPS) apparatus (KCE ${ }^{\circledR}$-FCT HP D 10-GB, FCT Systeme GmbH, Rauenstein, Germany) in a vacuum $\left(5 \cdot 10^{-2} \mathrm{mbar}\right)$. Sintering conditions were as follows: sintering temperature of $950-1350^{\circ} \mathrm{C}, 50-100 \mathrm{MPa}$ pressure and dwell time of 3-10 min. The heating rate employed was $100{ }^{\circ} \mathrm{C} \cdot \mathrm{min}^{-1}$ for the ramp-up and the cooling rate was set up to $\sim 200^{\circ} \mathrm{C} \cdot \mathrm{min}^{-1}$. SPS-produced samples from the Ni-W bimetallic system sintered at $1200{ }^{\circ} \mathrm{C}$ temperature and at a $50 \mathrm{MPa}$ pressure within a $5 \mathrm{~min}$ dwell time exhibited a $96 \%$ relative density.

XRD analysis demonstrated no dramatic change in phase composition after SPS processing (Figure 5c). Trace amounts of tungsten carbides observed are conditioned by the carbon uptake during sintering due to the tungsten's affinity to carbon at the sintering temperature; as powders were consolidated in graphite dies, graphite punches and protective graphite foil were also utilized. Vickers microhardness was measured to be $5.8 \pm 0.6 \mathrm{GPa}$ (HV1), which is comparable (or even higher) with results reported elsewhere [27-29] for the Ni-W alloys (4.5-5.5 GPa). The increased microhardness value is solely conditioned by an increased $\mathrm{W}$ amount in the Ni lattice structure. The microstructure of the alloy after sintering illustrates the homogeneous distribution of the tungsten-rich phase (light grey) in the nickel-rich phase matrix (dark grey) (Figure 5d). In addition, the influence of the sintering duration showed that $3 \mathrm{~min}$ of sintering is not enough to complete the process, as there are under-sintered areas; and $10 \mathrm{~min}$ resulted in fusion of the powder (Figure 6). 


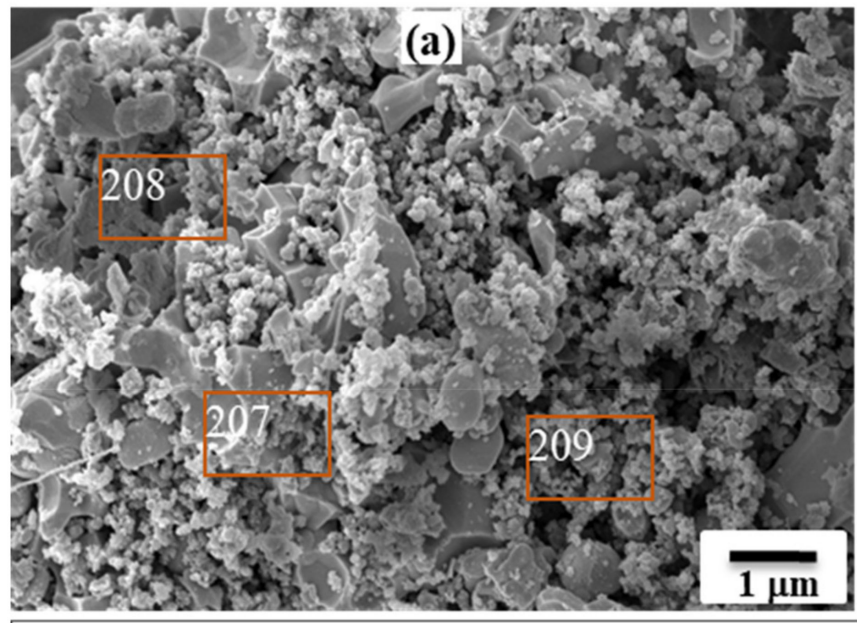

\begin{tabular}{|r|r|r|r|}
\hline Element/Spectrum & 267 & 268 & 269 \\
\hline W, wt\% & 34.13 & 37.19 & 72.81 \\
\hline $\mathbf{N i}$ wt $\%$ & 65.87 & 62.81 & 27.19 \\
\hline
\end{tabular}
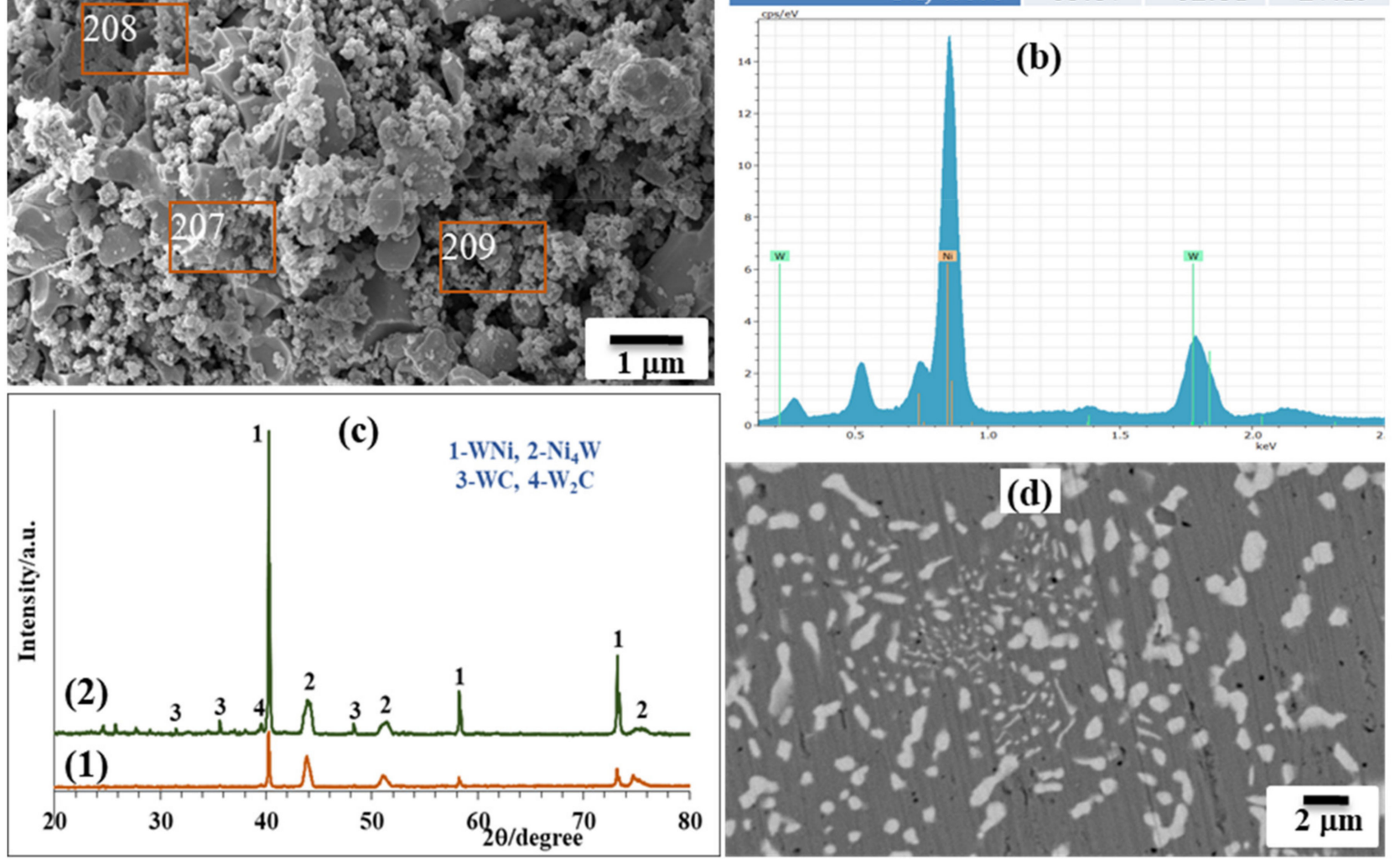

Figure 5. SEM/EDS of SHS-derived W-Ni composite powder after acid leaching (a,b), XRD pattern (c) before (1) and after SPS (2), SEM of surface of SPS-produced bulk sample, $5 \mathrm{~min}, 1200^{\circ} \mathrm{C}(\mathbf{d})$.
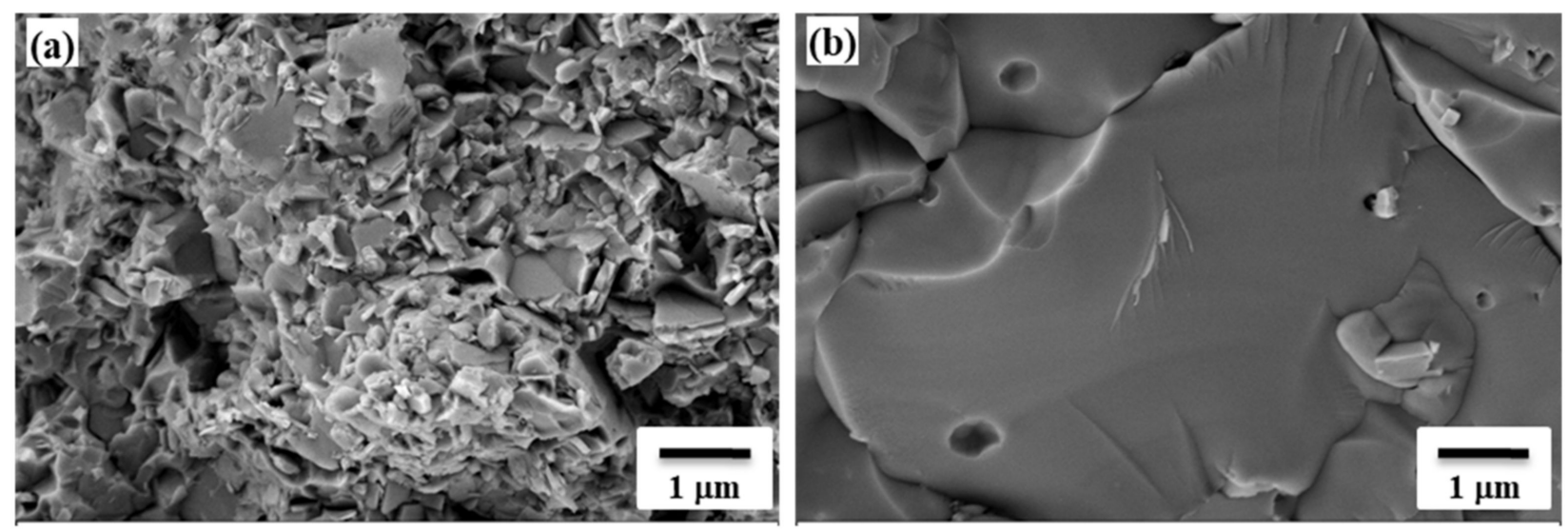

Figure 6. SEM images of fracture surface of SPS produced samples, (a) $3 \mathrm{~min},(\mathbf{b}) 10 \mathrm{~min}, \mathrm{~T}=1200{ }^{\circ} \mathrm{C}$.

EDS mapping of the fractured surface revealed the relatively homogeneous distribution of $\mathrm{Ni}$ and $\mathrm{W}$ elements (Figure 7). An increase in dwelling time of up to $10 \mathrm{~min}$ allowed to reduce the porosity to $1 \%$. A further increase in sintering duration is not desirable, as the $\mathrm{Ni}_{2} \mathrm{~W}_{4} \mathrm{C}$ phase may be formed from the surface to throughout the thickness of the sintered compact [30]. However, due to partial agglomeration and the pre-sintered state of the SHS-derived Ni-W powder, at a moderate sintering duration (up to $10 \mathrm{~min}$ ), the diffusion of carbon occurs only on the surface of powder particles, in contrast to mechanically alloyed powders. In particular, interfaces between grains of initial powders remain structurally different from the volume, offer tracks for quick carbon diffusion and favor the carbides' 
formation. In [31], mechanical alloying was used to both in situ fabricate the Ni-W solid solution alloy matrix from a Ni-30 wt \% W powder mixture and sinter coupons at $1000{ }^{\circ} \mathrm{C}$ during $3 \mathrm{~min}$ of a $96-97 \%$ relative density. Microstructural examinations showed the homogeneous distribution of phases in a micrometer range; however, the materials were characterized by some residual porosity. The authors suggested to utilize annealing prior to SPS, which may allow eliminating contaminations and increasing the relative density. Another approach to enhance the microstructural homogeneity and relative density of the $\mathrm{Ni}-\mathrm{W}$ composite is using $\mathrm{NiWO}_{4}$ as a precursor for $\mathrm{Ni}-\mathrm{W}$ alloy synthesis, or avoiding graphite dies during the sintering, which changes the reciprocal diffusion in the sintered material paired with h-BN or aluminum, as suggested in [32].
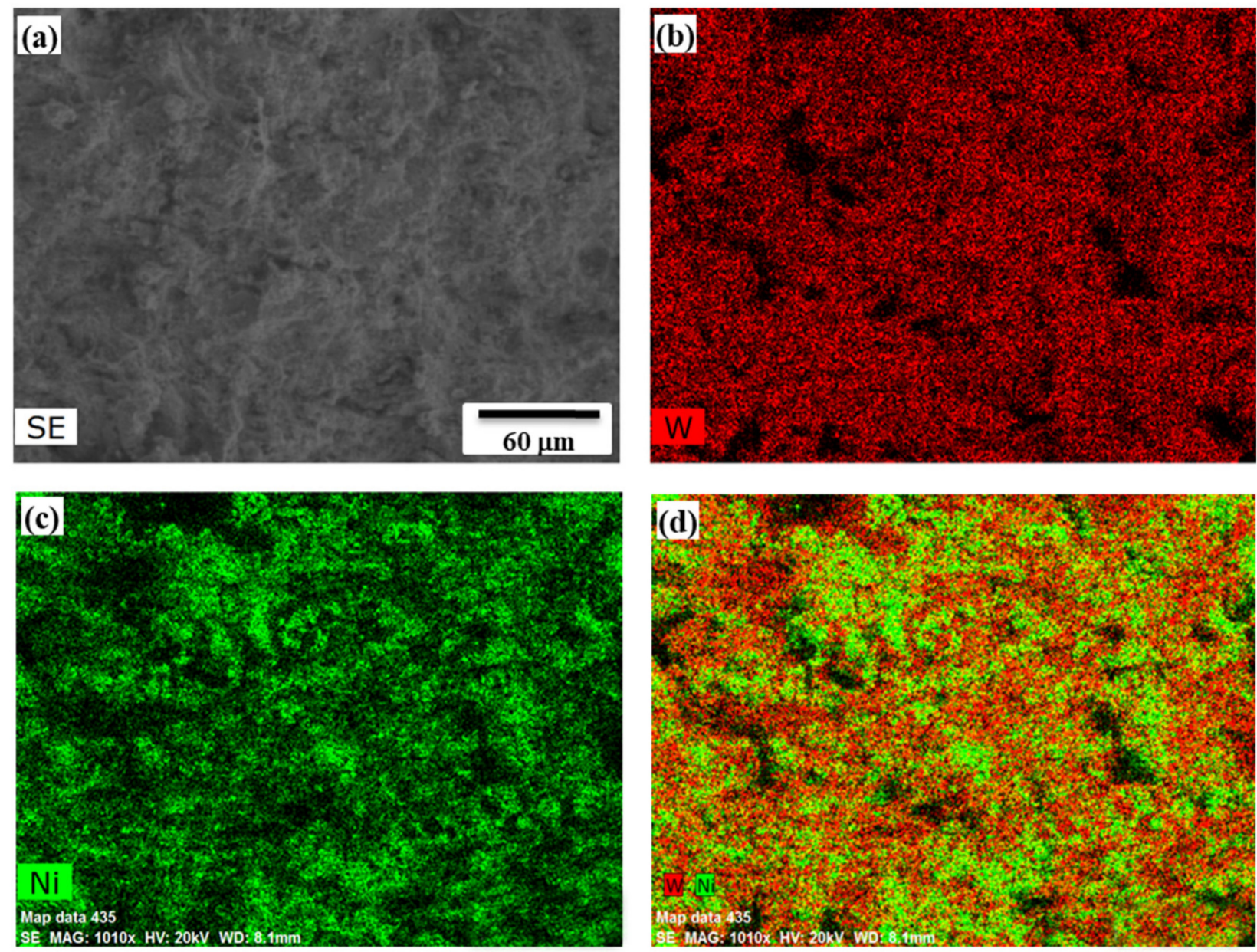

Figure 7. EDS mapping of fracture of the Ni-W SPS-produced sample, $5 \mathrm{~min}, 1200^{\circ} \mathrm{C}(\mathbf{a}), \mathrm{W}(\mathbf{b}), \mathrm{Ni}(\mathbf{c}), \mathrm{W}, \mathrm{Ni}(\mathbf{d})$.

\subsubsection{Copper-Molybdenum Bimetallic System}

As Mo-Cu materials with a homogeneous microstructure are difficult to achieve with conventional methods, various attempts have been carried out to produce fine and homogeneously dispersed Mo-Cu powders, utilizing a similar pathway for W-Ni and W-Cu composite materials. The increased scientific intrigue in $\mathrm{Mo}-\mathrm{Cu}$ materials is conditioned by the fact that Mo and $\mathrm{Cu}$ form a pseudo-alloy or composite material, where constituents are either the matrix or dispersing component depending on the ratio of $\mathrm{Mo}$ and $\mathrm{Cu}$. In order to achieve the purpose, oxygen-containing compounds of molybdenum and copper were jointly reduced utilizing the reactions' coupling approach and, in particular, the $\mathrm{Mg}+\mathrm{C}$ mixture was used as a combined reducer [24]. The real possibility of the joint and the complete reduction of $\mathrm{Mo}$ and $\mathrm{Cu}$ metals were manifested at a certain amount of reducing mixture (certain ratio of $\mathrm{Mg}$ and $\mathrm{C}$ ) and at moderate propagation velocity of the 
combustion wave. The obtained powders were consolidated using SPS in a vacuum at a sintering temperature of $950-1050{ }^{\circ} \mathrm{C}$, with the simultaneous exploitation of $100 \mathrm{MPa}$ pressure for a fixed dwell time $(3,5$ or $10 \mathrm{~min})$. The mould of $10 \mathrm{~mm}$ in diameter was charged with SHS-derived powders and heated up to a defined sintering temperature with a heating rate of $100-200^{\circ} \mathrm{C} \cdot \mathrm{min}^{-1}$.

Three pathways of powder synthesis were utilized.

One of the pathways is the preparation of Mo-Cu nanocomposites by the combination of energy-efficient solution combustion and the self-propagation of high-temperature synthesis. In the first step, a $\mathrm{MoO}_{2}+\mathrm{Cu}$ nanopowder mixture with an average particle size of $50 \mathrm{~nm}$ was prepared by SCS using ammonium heptamolybdate, copper nitrate as precursors and citric acid as a chelating reagent. During the second step via the SHS reduction of a fine $\mathrm{MoO}_{2}+\mathrm{Cu}$ powder mixture by a $\mathrm{Mg} / \mathrm{C}$ combined reducer, a Mo-Cu nanocomposite (with $50-70 \mathrm{~nm}$ size) was produced $\left(\mathrm{T}_{\mathrm{c}}=1250{ }^{\circ} \mathrm{C}\right.$ ) and subjected to SPS at $950{ }^{\circ} \mathrm{C}$ for $6 \mathrm{~min}$ and $100 \mathrm{MPa}$ pressure. SEM images demonstrate the particle size and shape preservation during the sintering (Figure 8a-c) [33]. The relative density of the samples was $97 \%$ and the Vickers hardness was around 3.8 GPa.
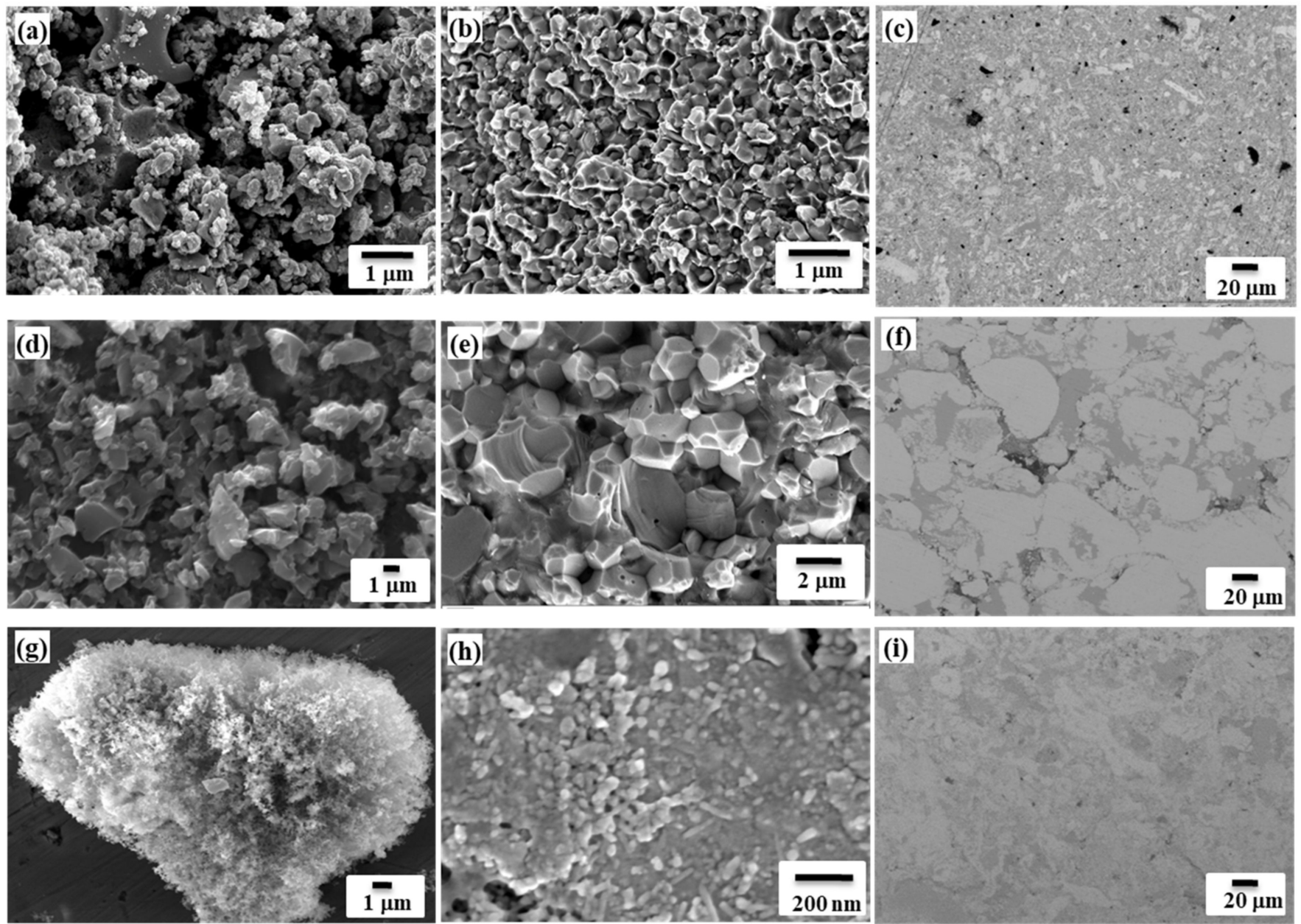

Figure 8. SEM of Mo-Cu powders obtained by different pathways (a,d,g); SEM images after SPS of samples fracture and surface of Cu-Mo obtained from SHS + SCS pathway (b,c); Cu-Mo obtained from SHS of oxides (e,f); Cu-Mo obtained from SHS of $\mathrm{CuMoO}_{4}$ salt $(\mathbf{h}, \mathbf{i}) ; \mathrm{T}=950{ }^{\circ} \mathrm{C}, \mathrm{P}=100 \mathrm{MPa}, \mathrm{t}=6 \mathrm{~min}, \mathrm{~d}=10 \mathrm{~mm}$.

Using the second approach, Mo-Cu powders of 1-3 $\mu \mathrm{m}$ particle size were produced by the SHS of the $\mathrm{CuO}-\mathrm{MoO}_{3}-\mathrm{yMg}-\mathrm{xC}$ mixture $\left(\mathrm{y}=1.2 ; \mathrm{x}=2.1-2.2 \mathrm{~mol} ; \mathrm{T}_{\mathrm{c}}=1300{ }^{\circ} \mathrm{C}\right)$ from copper (II) oxide (High grade, STANCHEM, Poland, $<40 \mu \mathrm{m}$ ), molybdenum (VI) (High grade, Pobedit Company, Russia, $<15 \mu \mathrm{m})$ oxide, carbon black (P-803, Russia, $<1 \mu \mathrm{m})$ and 
magnesium (MPF-3, Russia, 150-300 $\mu \mathrm{m}$ ) (Figure 3). Powders consolidated at identical conditions are presented in Figure 8d-f. Sintered counter bodies comprise a 4.1 GPa Vickers hardness and a 95\% relative density. In contrast to the sample derived by the first pathway, the Mo-Cu compact here has more porosity, but a higher hardness, most likely conditioned by a coarser grain size.

A similar approach was utilized for the preparation of the Mo-Cu bimetallic system from copper molybdates derived by calcination (I) and coprecipitation (II) methods, with a subsequent consolidation [34].

According to the thermodynamic modelling and primary combustion experiments of the copper molybdate reduction using a $\mathrm{Mg}+\mathrm{C}$ combined reducer, the amount of magnesium was selected as 1.2-1.5 mol in order to achieve complete reduction. The combustion velocity and the combustion temperature tend to slightly decrease with an increase in the carbon content in the mixture with copper molybdate derived by coprecipitation, whereas using calcined $\mathrm{CuMoO}_{4}$ caused a substantial drop in the combustion velocity, which was registered by the addition of an even insignificant amount of carbon. The observed pattern was explained by the composition of $\mathrm{CuMoO}_{4}$ (II) when it was calcined for $1 \mathrm{~h}$, and copper hydroxymolybdate decomposed to copper molybdate during the calcination process and combustion parameters of the calcined $\mathrm{CuMoO}_{4}$ (II) powder resembled the behavior of copper molybdate(I). With the addition in carbon, the reduction was accomplished by the formation of both metals. Accordingly, the corresponding mixtures with both salts, $\mathrm{CuMoO}_{4}(\mathrm{I})+1.2 \mathrm{Mg}+2.2 \mathrm{C}$ and $\mathrm{CuMoO}_{4}(\mathrm{II})+1.5 \mathrm{Mg}+1.6 \mathrm{C}$, were selected for $\mathrm{Mo}-\mathrm{Cu}$ alloy preparation. Despite the different amounts of reducers in the reactive mixture, both salts followed a similar reduction pathway, firstly converting into salts of $\mathrm{Cu}_{2} \mathrm{MoO}_{5}$ and $\mathrm{Cu}_{6} \mathrm{Mo}_{5} \mathrm{O}_{18}$, then $\mathrm{Cu}$ and $\mathrm{MoO}_{2}$ by carbon, and, at the end, into molybdenum by the magnesiothermic reduction of $\mathrm{MoO}_{2}$ [34].

XRD examinations of the final products indicate the characteristic diffraction lines of molybdenum and copper after the acid leaching procedure, and the complete elimination of the $\mathrm{MgO}$ byproduct. SEM micrographs of the target $\mathrm{Mo}-\mathrm{Cu}$ products derived from both salts display the existence of spherical nanoparticles (50-100 nm) of a narrow distribution (Figure 8g).

For the consolidation of produced SHS nanopowders Mo-Cu (1:1), the spark plasma sintering (SPS) was utilized. The sintering temperature has a detrimental effect on the density of the produced specimens. Particularly, when the sintering temperature increases by $50{ }^{\circ} \mathrm{C}$ (from 950 to $1000{ }^{\circ} \mathrm{C}$ ), the increase in relative density by $10 \%$ occurs. In parallel, a shorter dwelling duration causes grains refinement and, consequently, an increase in hardness. According to multiparametric studies, the optimum sintering temperature was considered to be $1000{ }^{\circ} \mathrm{C}$ applied during $3 \mathrm{~min}$ for Mo-CuSHS-derived powders. Geometrical and Archimedes densities of Mo-Cu coupons fabricated at optimized conditions were measured as $8.8 \mathrm{~g} \mathrm{~cm}^{-3}$. Accordingly, the relative density was $>90 \%$. Microhardness measurements using the Vickers indentation method showed that the HV5 of the Mo-Cu composite makes 3.2 GPa, which exceeds the hardness of pure copper by around ten times and the hardness of molybdenum by more than two times. High-energy ball milling (HEBM) for $1 \mathrm{~h}$ certified the increase in hardness of up to 3.8 GPa due to grain refinement; however, the substantial influence of the pre-treatment on the relative density of the compacts was not established. The hardness values for these nanostructured alloys exceeds twice the hardness of the materials prepared by mechanical alloying. The difference is obviously ascribed to the preserved nanostructure at a combination of SHS and SPS techniques (Figure 8h,i).

According to the literature data, Mo-Cu billets sintered without any mechanical pretreatment comprised spheroidal particles of molybdenum, and the room between them was captured by copper; the maximum density achieved was $88 \%$. A commercial powder mixture of $\mathrm{Cu}$ and Mo being subjected to intense HEBM for $1 \mathrm{~h}$ led to the formation of a fine structured composite, according to the XRD pattern [35], and $\mathrm{Cu}$ and Mo constituents were intermixed at the submicron level; however, SPS at similar sintering conditions did 
not allow to achieve full density compacts. The comparative analysis of SEM images and the characterization of compacts obtained from SHS-derived powders and HEBM processes demonstrate the privilege of SHS powders by path 1 and path 3 in terms of the microstructural homogeneity of the sintered counterpart and the microhardness. However, for the fabrication of high-density Mo-Cu compacts (98-99\%), the laborious and expensive method of the liquid phase sintering of pre-alloyed Mo-Cu nanopowder $(100-200 \mathrm{~nm})$ is still preferable [36].

Further, it was proposed to utilize Mo-Cu composite powders with a molar ratio of constituent metals of Mo: $\mathrm{Cu}=1: 1$, obtained from oxide precursors in a combustion mode (Figures 1c and 3), for further densification by the selective laser melting (SLM) technique in order to obtain dense cubic and lattice structured Mo-Cu shapes with the help of the SLM apparatus ReaLizer $50 \mathrm{GmbH}$ (Frankfurt, Germany). Sintering conditions, such as the laser current $(\mathrm{mA})$, scan $\left(\mathrm{mm} \cdot \mathrm{s}^{-1}\right)$, point distance $(\mu \mathrm{m})$ and exposure time $(\mu \mathrm{s})$, were adjusted for each system under consideration. The SLM machine employs a high-powered continuous-wave laser, which is modulated to function like a pulsed laser system. The Yb:YAG fiber laser, with a maximum power of $120 \mathrm{~W}$ and wavelength of $1.07 \mu \mathrm{m}$, was used to solidify the structures. The process of SLM was performed in an argon atmosphere of a high purity (99.999 vol.\%). Mo-Cu lattice structures showed poor sinterability, and the splashing of the powder and deterioration of the designed structure occurred due to the fine-grained powder. Bulk samples sintered at a $900 \mathrm{~mA}$ laser current comprised an $85 \%$ relative density. With an increase in the laser current of up to $2500 \mathrm{~mA}$ (exposure time $125 \mu \mathrm{s}$, point distance $10 \mu \mathrm{m}$ ), a relative density of $93 \%$ was achieved, which is comparable with the W-Cu composite obtained by the SLM method (91.6\%) [37]. The laser current was revealed to be the most determinative parameter to achieve high relative density compacts of $\mathrm{Mo-} \mathrm{Cu}$ and $\mathrm{W}-\mathrm{Cu}$. Considering the higher laser absorptivity of tungsten and molybdenum compared to copper, it is assumed that refractory metals absorb more laser energy than copper, resulting in the formation of a $\mathrm{Cu}$ molten pool and the solid-state sintering of a refractory skeleton almost contemporaneously. Hence, the SLM method has a perspective for the preparation of pseudoalloys comprising two or more distinctly different metals.

\subsubsection{Thermochemically Coupled Synthesis of $\mathrm{AlMgB}_{14}-\mathrm{TiB}_{2}$ System with Subsequent Sintering}

The thermochemical coupling approach was used to deliver $\mathrm{AlMgB}_{14}-\mathrm{TiB}_{2}$ composite materials by self-propagating high-temperature synthesis for subsequent SPS compaction at $1470{ }^{\circ} \mathrm{C}$ for a duration of $5 \mathrm{~min}$ [38]. Ti (OJSC Polema), (purity $99.2 \%$, average particle size $140 \mu \mathrm{m}$ ), $\mathrm{Al}_{12} \mathrm{Mg}_{17}$ (Original powder) (purity 99.2\%, average particle size $20 \mu \mathrm{m}$ ) and boron (OJSC Aviabor), (purity 98.8\%, average particle size $0.6 \mu \mathrm{m}$ ) were used as precursors in combustion experiments to prepare $\mathrm{AlMgB}_{14}-\mathrm{TiB}_{2}$ composite materials. The powder mixture of $\mathrm{Ti}$ and $\mathrm{B}$ elements was taken as a donor mixture, and the acceptor mixture encompassed the intermetallic powder of $\mathrm{Al}_{12} \mathrm{Mg}_{17}$ with the amorphous boron powder. For the combustion experiments, $(\mathrm{Ti}+2 \mathrm{~B})$ and $\mathrm{Al}_{12} \mathrm{Mg}_{17}: \mathrm{B}$ powder mixtures were mixed in a mass ratio of $70 \mathrm{wt} \%\left(\mathrm{Al}_{12} \mathrm{Mg}_{17}: \mathrm{B}\right)+30 \mathrm{wt} \%(\mathrm{Ti}+2 \mathrm{~B})$ in ethanol. Samples with a diameter of $23 \mathrm{~mm}$ were cold-pressed from the dried powder mixture. Then, the samples were placed in an SHS reactor. The reactor was evacuated and filled with argon to a pressure of $2.5 \mathrm{MPa}$. After the reaction initiation in the Ti-B- $\mathrm{Al}_{12} \mathrm{Mg}_{17}$ system, the heating zone was formed enough to melt $\mathrm{Al}_{12} \mathrm{Mg}_{17}$ particles. The melt dissolved the Ti and $\mathrm{B}$ elements and the temperature increased up to $1580^{\circ} \mathrm{C}$ as a result of the exothermic reaction of the $(\mathrm{Ti}+2 \mathrm{~B})$ donor mixture. The heat released contributed to the synthesis reaction in the acceptor mixture, with a parallel decrease in the temperature down to $1400^{\circ} \mathrm{C}$. As the donor reaction is exothermic, a further increase in the temperature up to $1550{ }^{\circ} \mathrm{C}$ was registered before cooling. Under the influence of the high temperature and with enough time for cooling, $\mathrm{TiB}_{2}$ crystal grains grew. The SHS-derived powder material contained particles with a $\sim 1 \mu \mathrm{m}$ average size (Figure 9). $\mathrm{TiB}_{2}$ particles were in the form of agglomerates of up to $30 \mu \mathrm{m}$ in size due to recrystallization under the influence of elevated temperatures. 

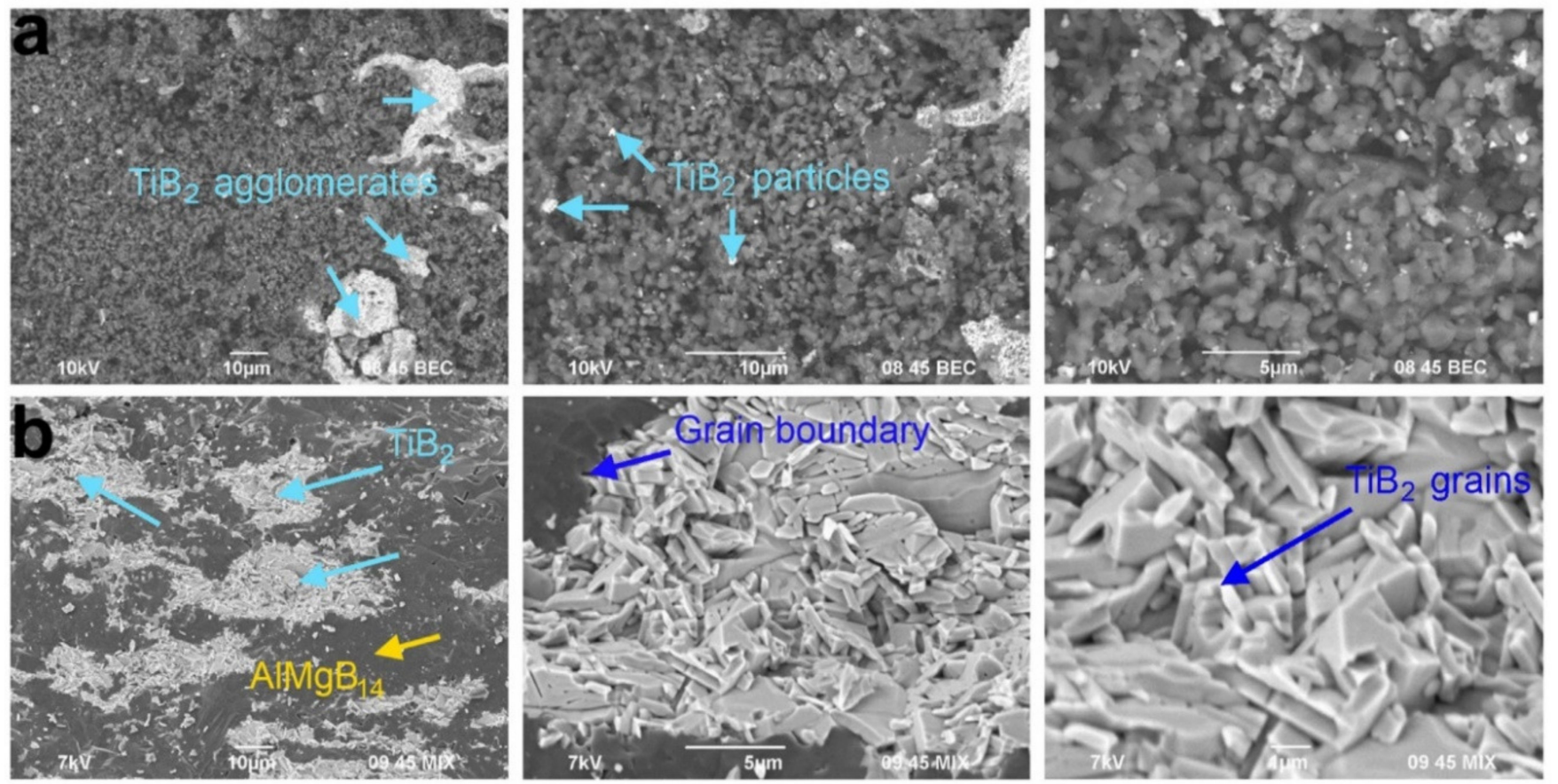

Figure 9. SEM images of SHS powder (a) and dense samples sintered by SPS at $1450{ }^{\circ} \mathrm{C}(\mathbf{b})$. Reprinted from Nikitin et al., 2020 with copyright permission, Ceramics International [38].

The simultaneous consolidation and sintering of the mixture were conducted at a temperature $\left(\mathrm{T}_{\mathrm{s}}\right)$ of 1450 and $1470{ }^{\circ} \mathrm{C}$, with $70 \mathrm{MPa}$ of pressure. Heating rates $\left(\mathrm{V}_{\mathrm{h}}\right)$ of 50 and $250{ }^{\circ} \mathrm{C} / \mathrm{min}$ were used during the sintering. After the sintering without holding, the estimated average particle size of both phases, $\mathrm{AlMgB}_{14}$ and $\mathrm{TiB}_{2}$, was around $3-5 \mu \mathrm{m}$. The ceramic structure was not uniform, but was fully dense and exhibited an enhanced hardness of $32.1 \mathrm{GPa}$. The composite material demonstrated comparable characteristics to the material obtained from the hot pressed $\left(1400{ }^{\circ} \mathrm{C}, 2 \mathrm{~h}\right)$ mixture of SHS-derived $\mathrm{AlMgB}_{14}$ and commercial $\mathrm{TiB}_{2}[39]$ in terms of initial powder (particle size and distribution) and final compact (density and hardness).

\subsection{Discussion of the Results}

Comparing the properties of $\mathrm{W}-\mathrm{Cu}$ composites that were produced by both SHS and blending and consolidated by the same method (HEC), the advantages of SHS-produced powders are obvious in terms of the density and microhardness of the composite, whereas the SPS consolidation of W-Cu nanopowders did not allow to achieve a density $>90 \%$ [40] (Table 1, Figure 10). However, the particle size of the initial precursor had a strong influence on the hardness value. After SPS, the W-Ni compacts prepared from powders derived by SHS exhibit an enhanced hardness as compared to the compacts produced from the blended precursors. There are no literature data on the consolidation of the Ni-W system via HEC; however, Fe-Ni-W and Al-Ni-W were successfully compacted by HEC [41,42]. $\mathrm{Ni}-\mathrm{W}$ materials are usually obtained by powder metallurgy methods, such as long-term sintering at a temperature of $1350-1500{ }^{\circ} \mathrm{C}$. In the presence of a liquid phase, the tungsten powder is recrystallized with the formation of almost spherical particles, which are tens of times larger than the particles of the initial powder. The production of the W-Ni powder is possible by SHS at a combustion temperature below the melting point of the constituents, which contributes to the fine powder production. $\mathrm{Cu}$-Mo materials with a homogeneous microstructure are difficult to achieve with conventional methods. Bulks produced from SCS and MA-derived Cu-Mo composite powders demonstrated similar properties after SPS and up to a $97 \%$ density. MA is shown to have a beneficial influence on the mechanical properties. Up to now, for the fabrication of high-density Cu-Mo compacts (98-99\%), the laborious and expensive method of the liquid phase sintering of the pre-alloyed Mo- 
$\mathrm{Cu}$ nanopowder $(100-200 \mathrm{~nm})$ is still preferable. The SLM method is shown to have a perspective for the preparation of pseudoalloys comprising two or more distinctly different metals, but insufficient data are available in the literature so far.

Table 1. Comparative overview of the systems under consideration produced by different methods (SHS-self-propagating high-temperature synthesis, SCS-solution combustion synthesis, MA-mechanical alloying, HEC-hot explosive consolidation/compaction, AM-additive manufacturing, HP-hot pressing, SLM-selective laser melting, SPS-spark plasma sintering).

\begin{tabular}{|c|c|c|c|c|c|c|}
\hline Material * & $\begin{array}{l}\text { Particle Size of Powder, } \\
\text { Production Method }\end{array}$ & $\begin{array}{l}\text { Sintering } \\
\text { Method }\end{array}$ & $\begin{array}{l}\text { Sintering } \\
\text { Conditions }\end{array}$ & $\begin{array}{l}\text { Relative } \\
\text { Density }\end{array}$ & Hardness & Refs \\
\hline $\mathrm{W}-\mathrm{Cu}$ & $\begin{array}{l}\text { From submicron up to } \\
\text { tenths of microns, SHS }\end{array}$ & HEC & $\begin{array}{l}1050{ }^{\circ} \mathrm{C}, \\
\text { pre-densified } \\
\text { at } 1.5 \mathrm{t}\end{array}$ & Fully dense & $370 \mathrm{~kg} \cdot \mathrm{mm}^{-2}$ & [10] \\
\hline $\mathrm{W}-\mathrm{Cu}$ & $\begin{array}{l}\text { From nano and micron } \\
\text { size } \\
\text { elementary powders, } \\
\text { blending }\end{array}$ & HEC & $900{ }^{\circ} \mathrm{C}, 5 \mathrm{GPa}$ & $\begin{array}{l}\text { Near full } \\
\text { density }\end{array}$ & $\begin{array}{c}126-200 \\
\mathrm{~kg} \cdot \mathrm{mm}^{-2}\end{array}$ & {$[11]$} \\
\hline $\mathrm{W}-10 \mathrm{wt} \% \mathrm{Cu}$ & MA & HEC & $950^{\circ} \mathrm{C}, 3 \mathrm{~min}$ & $<95$ & $4.34 \mathrm{GPa}$ & [25] \\
\hline $\mathrm{W}-\mathrm{Cu}$ & $\begin{array}{l}\text { Milling of nanopowders } \\
\text { of W (40-60 nm) and Cu } \\
(\sim 50 \mathrm{~nm})\end{array}$ & SPS & $950{ }^{\circ} \mathrm{C}, 10 \mathrm{~min}$ & 90 & $3.11 \mathrm{GPa}$ & [40] \\
\hline $\mathrm{Ni}-\mathrm{W}$ & Submicron powder, SHS & SPS & $\begin{array}{c}1200^{\circ} \mathrm{C} \\
50 \mathrm{MPa}, 5 \mathrm{~min}\end{array}$ & 96 & $5.8 \pm 0.6 \mathrm{GPa}$ & [26] \\
\hline $\mathrm{Ni}-\mathrm{W}$ & $\begin{array}{l}\mathrm{Ni} \text { and } \mathrm{W} \text { particles is } \\
14.3 \mu \mathrm{m} \text { and } 0.6 \mu \mathrm{m} \\
\text { powder blending }\end{array}$ & SPS & $1000^{\circ} \mathrm{C}, 30 \mathrm{~min}$ & - & $486 \pm 65 \mathrm{HV}$ & {$[27]$} \\
\hline $\mathrm{Mo}-\mathrm{Cu}$ & $50-70 \mathrm{~nm}, \mathrm{SCS}$ & SPS & $\begin{array}{l}950^{\circ} \mathrm{C}, 100 \\
\mathrm{MPa}, 6 \mathrm{~min}\end{array}$ & 97 & $3.8 \mathrm{GPa}$ & {$[33]$} \\
\hline $\mathrm{Mo}-\mathrm{Cu}$ & $1-3 \mu \mathrm{m}, \mathrm{SHS}$ & SPS & $\begin{array}{l}950^{\circ} \mathrm{C}, 100 \\
\mathrm{MPa}, 6 \mathrm{~min}\end{array}$ & 95 & $4.1 \mathrm{GPa}$ & - \\
\hline $\mathrm{Mo}-\mathrm{Cu}$ & 50-100 nm, SHS & SPS & $1000{ }^{\circ} \mathrm{C}, 3 \mathrm{~min}$ & $>90$ & $3.8 \mathrm{GPa}$ & {$[34]$} \\
\hline $\mathrm{Mo}-\mathrm{Cu}$ & $1-3 \mu \mathrm{m}, \mathrm{SHS}$ & SLM & $2500 \mathrm{~mA}$ & 93 & - & - \\
\hline $\mathrm{Mo}-\mathrm{Cu}$ & $\begin{array}{c}\text { MA } 60 \mathrm{~min} \text {, precursors } \\
45-100 \mu \mathrm{m} \mathrm{Cu}, \\
\text { Mo } 2-4.5 \mu \mathrm{m}\end{array}$ & SPS & $950^{\circ} \mathrm{C}, 10 \mathrm{~min}$ & 97 & $3.68-3.88 \mathrm{GPa}$ & {$[35]$} \\
\hline $\mathrm{AlMgB}_{14}-30 \% \mathrm{TiB}_{2}$ & $\begin{array}{c}\sim 1 \mu \mathrm{m} \text { (agglomerates up } \\
\text { to } 30 \mu \mathrm{m}), \text { SHS }\end{array}$ & SPS & $1470{ }^{\circ} \mathrm{C}, 5 \mathrm{~min}$ & Fully dense & $32.1 \mathrm{GPa}$ & {$[38]$} \\
\hline $\begin{array}{l}\mathrm{AlMgB}_{14^{-}} \\
30 \% \mathrm{TiB}_{2}\end{array}$ & 5-10 $\mu \mathrm{m}$, SHS & $\mathrm{HP}$ & $1400^{\circ} \mathrm{C}, 2 \mathrm{~h}$ & 99 & $31.2 \mathrm{GPa}$ & [39] \\
\hline $\begin{array}{l}\mathrm{AlMgB}_{14^{-}} \\
30 \% \mathrm{TiB}_{2}\end{array}$ & $\sim 1 \mu \mathrm{m}, \mathrm{MA}$ & $\mathrm{HP}$ & $1400^{\circ} \mathrm{C}, 2 \mathrm{~h}$ & 99 & $28.4 \mathrm{GPa}$ & [39] \\
\hline
\end{tabular}

* Me'-Me" systems of 1:1 molar ratio were considered.

The SHS-derived $\mathrm{AlMgB}_{14-30}-\mathrm{TiB}_{2}$ composite that was compacted by SPS and HP methods demonstrated relatively similar properties: a small difference in hardness could be attributed to a slightly higher (by $70{ }^{\circ} \mathrm{C}$ ) sintering temperature. The MA-produced composite of a similar particle size and phase distribution exhibited a comparably lower hardness. 


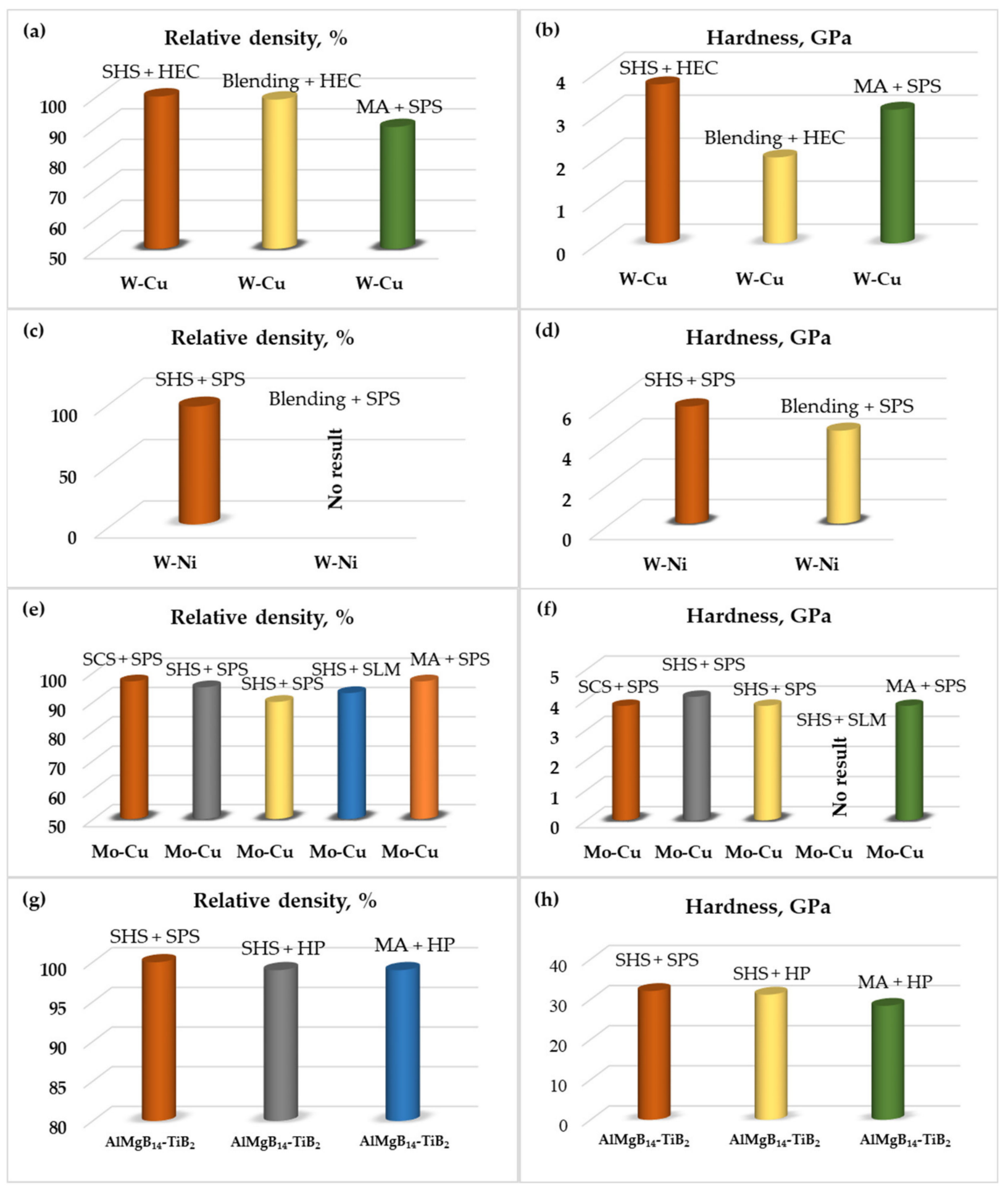

Figure 10. Plots of hardness and relative density values for the systems under consideration; W-Cu (a,b), W-Ni (c,d), Mo-Cu $(\mathbf{e}, \mathbf{f}), \mathrm{AlMgB}_{14}-\mathrm{TiB}_{2}(\mathbf{g}, \mathbf{h})$.

\section{Conclusions}

The design of composite systems by coupling a low exothermic reaction with a high exothermic one contributed to the effective control over the thermal regime of the selfsustaining process and to the preparation of applicable powder precursors for the fabrication of counter-bodies. In particular, hot explosively compacted specimens obtained from $\mathrm{W}-\mathrm{Cu}$ (1:1 molar ratio) fine SHS powders demonstrated an approximately two times enhanced microhardness as compared to those obtained by mechanical alloying. Mi- 
crostructural observations, in combination with spectral analysis, indicated a homogeneous microstructure evolution of the obtained $\mathrm{W}-\mathrm{Cu}$ bimetallic system, and a relative density near to the theoretical value. The supercooling of the material after HEC and the anisotropy in the surface energy of the tungsten-copper interface promoted a highly textured dendrite microstructure, which may provide an enhanced plasticity when exposed to high thermal loads, suggesting them as potential candidates for HT coatings.

The fine microstructure formation was observed at the combustion synthesis of Ni$\mathrm{W}$ nanopowder at moderate and tailored conditions. The average value for the Vickers microhardness $(5.8 \pm 0.6 \mathrm{GPa}(\mathrm{HV} 1))$ was achieved as being higher than the values reported elsewhere for the $\mathrm{W}-\mathrm{Ni}$ alloys $(4.5-5.5 \mathrm{GPa})$, which was as a result of an increased $\mathrm{W}$ amount in the Ni lattice structure due to the pre-sintered state of the SHS-derived Ni-W powder. In addition, due to partial agglomeration and the pre-sintered state of the Ni-W powder, at a moderate sintering duration (of up to $10 \mathrm{~min}$ ), the diffusion of carbon occurs only on the surface of the powder particles, in contrast to mechanically alloyed powders, and contributes to the relative density of the W-Ni composite material.

The comparative analysis of Mo-Cu compacts obtained from SHS-derived powders and HEBM processes demonstrated the privilege of SHS powders obtained from $\mathrm{CuMoO}_{4}$ salt and using SCS methods in terms of the microstructural homogeneity of the sintered counterpart and the microhardness. However, for the fabrication of full density Mo- $\mathrm{Cu}$ compacts, the liquid phase sintering of pre-alloyed Mo-Cu nanopowder (100-200 nm) is still preferable. However, the perspective of the SLM method for the preparation of Mo-Cu and $\mathrm{W}-\mathrm{Cu}$ pseudoalloys was successfully demonstrated, owing to the higher laser absorptivity of tungsten and molybdenum compared to copper, assuming a contemporaneous formation of the $\mathrm{Cu}$ molten pool and the solid-state sintering of the refractory skeleton. SPS-produced counter-bodies from the thermochemically coupled $\mathrm{AlMgB}_{14}-\mathrm{TiB}_{2}$ system exhibited enhanced mechanical properties. In general, SHS-derived powders obtained by coupled reactions, owing to specific microstructural features, demonstrated themselves as good candidates for subsequent efficient consolidation.

Author Contributions: Conceptualization, S.A.; methodology, S.A., S.K. and I.H.; investigation, S.A.; resources, S.A. and I.H.; data curation, S.A., S.K. and I.H.; writing-original draft preparation, S.A.; writing-review and editing, S.A., S.K. and I.H.; visualization, S.A.; funding acquisition, S.A. and I.H. All authors have read and agreed to the published version of the manuscript.

Funding: This work was supported by Estonian Research Council, Estonia, under Grants PSG220 (S.A.) and PRG643 (I.H.).

Institutional Review Board Statement: Not applicable.

Informed Consent Statement: Not applicable.

Data Availability Statement: The data supporting the findings of this study are available within the article.

Conflicts of Interest: The authors declare no conflict of interest.

\section{References}

1. Merzhanov, A.G. History and recent developments in SHS. Ceram. Int. 1995, 21, 371-379. [CrossRef]

2. Varma, A.; Rogachev, A.S.; Mukasyan, A.S.; Hwang, S. Combustion synthesis of advanced materials: Principles and applications. In Advances in Chemical Engineering; Academic Press: Cambridge, MA, USA, 1998; Volume 24, pp. 79-226.

3. Liu, G.; Li, J.; Chen, K. Combustion synthesis of refractory and hard materials: A review. Int. J. Ref. Metals Hard Mater. 2013, 39, 90-102. [CrossRef]

4. Mishra, S.K.; Das, S.; Pathak, L.C. Defect structures in zirconium diboride powder prepared by self-propagating high-temperature synthesis. Mat. Sci. Eng. A 2004, 364, 249-255. [CrossRef]

5. Orrù, R.; Cao, G. Spark Plasma Sintering of SHS Powders. In Concise Encyclopedia of Self-Propagating High-Temperature Synthesis; Elsevier: Amsterdam, The Netherlands, 2017; pp. 349-351.

6. Yi, H.C.; Moore, J.J. Self-propagating high-temperature (combustion) synthesis (SHS) of powder-compacted materials. J. Mater. Sci. 1990, 25, 1159-1168. [CrossRef] 
7. Korosteleva, E.N.; Korzhova, V.V.; Krinitcyn, M.G. Sintering behavior and microstructure of TiC-Me composite powder prepared by SHS. Metals 2017, 7, 290. [CrossRef]

8. Kwon, Y.S.; Dudina, D.V.; Korchagin, M.A.; Lomovsky, O.I. Microstructure changes in $\mathrm{TiB}_{2}$-Cu nanocomposite under sintering. J. Mater. Sci. 2004, 39, 5325-5331. [CrossRef]

9. Morsi, K. Combustion synthesis and the electric field: A review. Int. J. Self-Propagating High-Temp. Synth. 2017, 26, 199-209. [CrossRef]

10. Aydinyan, S.V.; Kirakosyan, H.V.; Zakaryan, M.K.; Abovyan, L.S.; Kharatyan, S.L.; Peikrishvili, A.; Mamniashvili, G.; Godibadze, B.; Chagelishvili, E.S.; Lesuer, D.R.; et al. Fabrication of $\mathrm{Cu}-\mathrm{W}$ nanocomposites by integration of self-propagating high-temperature synthesis and hot explosive consolidation technologies. Eurasian Chem. Technol. J. 2018, 20, 301-309. [CrossRef]

11. Godibadze, B.A.; Chagelishvili, E.S.; Peikrishvili, A.B.; Tsiklauri, M.V.; Dgebuadze, A.A. Explosive fabrication of Cu-C and Cu-W materials. Procedia Earth Planet. Sci. 2015, 15, 448-453. [CrossRef]

12. Sing, S.L.; Yeong, W.Y.; Wiria, F.E.; Tay, B.Y.; Zhao, Z.; Zhao, L.; Tian, Z.; Yang, S. Direct selective laser sintering and melting of ceramics: A review. Rapid Prototyp. J. 2017, 23, 611-623. [CrossRef]

13. Kharatyan, S.L.; Merzhanov, A.G. Coupled SHS reactions as a useful tool for synthesis of materials: An overview. Int. J. Self-Propagating High-Temp. Synth. 2012, 21, 59-73. [CrossRef]

14. Korchagin, M.A. Thermal explosion in mechanically activated low-calorific-value compositions. Combust. Explos. Shock. Waves 2015, 51, 578-586. [CrossRef]

15. Filimonov, V.Y.; Korchagin, M.A.; Smirnov, E.V.; Sytnikov, A.A.; Yakovlev, V.I.; Lyakhov, N.Z. Kinetics of mechanically activated high temperature synthesis of $\mathrm{Ni3Al}$ in the thermal explosion mode. Intermetallics 2011, 19, 833-840. [CrossRef]

16. Pribytkov, G.A.; Baranovskiy, A.V.; Korzhova, V.V.; Krinitcyn, M.G. Mechanoactivated SHS in Ferrotitanium-Carbon Black Powder Mixtures. Int. J. Self-Propagating High-Temp. Synth. 2020, 29, 61-63. [CrossRef]

17. Liu, L.; Aydinyan, S.; Minasyan, T.; Hussainova, I. SHS produced TiB 2 -Si powders for selective laser melting of ceramic-based composite. Appl. Sci. 2020, 10, 3283. [CrossRef]

18. Aydinyan, S.V.; Kharatyan, S.L. Thermally and kinetically coupled reactions at combustion synthesis of materials, monograph. In Technological Combustion; Alymov, A., Ed.; Russian Academy of Sciences: Moscow, Russia, 2018; Volume 17, pp. 429-451. (In Russian)

19. Khachatryan, G.L.; Arutyunyan, A.B.; Kharatyan, S.L. Activated combustion of a silicon-carbon mixture in nitrogen and SHS of $\mathrm{Si}_{3} \mathrm{~N}_{4}$-SiC composite ceramic powders and silicon carbide. Combust. Explos. Shock. Waves 2006, 42, 543-548. [CrossRef]

20. Wang, J.; Long, F.; Wang, W.; Mo, S.; Zou, Z.; Fu, Z. Reaction coupling preparation of high sintering activity boron carbide nano-powders. Ceram. Int. 2016, 42, 6969-6977. [CrossRef]

21. Amosov, A.P.; Samboruk, A.R.; Yatsenko, I.V.; Yatsenko, V.V. TiC-Fe powders by coupled SHS reactions: An overview. Int. J. Self-Propagating High-Temp. Synth. 2019, 28, 10-17. [CrossRef]

22. Chumakov, Y.A.; Knyazeva, A.G.; Pribytkov, G.A. Influence of Titanium Excess in a Ti-Si Reaction Mixture on the Synthesis of a Composite in a Combustion Wave. Theor. Found. Chem. Eng. 2021, 55, 490-503. [CrossRef]

23. Deganello, F.; Tyagi, A.K. Solution combustion synthesis, energy and environment: Best parameters for better materials. Prog. Cryst. Growth Charact. Mater. 2018, 64, 23-61. [CrossRef]

24. Aydinyan, S.V.; Kirakosyan, H.V.; Kharatyan, S.L. Cu-Mo composite powders obtained by combustion-coreduction process. Int J. Ref. Metals Hard Mater. 2016, 54, 455-463. [CrossRef]

25. Zhou, Q.; Chen, P. Characterization of fine-grained W-10 wt.\% Cu composite fabricated by hot-shock consolidation. Int. J. Ref. Metals Hard Mater. 2015, 52, 137-142. [CrossRef]

26. Zakaryan, M.K.; Aydinyan, S.V.; Kharatyan, S.L. Combustion synthesis and consolidation of Ni-W nanocomposite material. Ceram. Modern Tech. 2018, 1, 67-74. [CrossRef]

27. Sadat, T.; Dirras, G.; Tingaud, D.; Ota, M.; Chauveau, T.; Faurie, D.; Vajpai, S.; Ameyama, K. Bulk Ni-W alloys with a compositelike microstructure processed by spark plasma sintering: Microstructure and mechanical properties. Mater. Des. 2016, 89, 1181-1190. [CrossRef]

28. Genç, A.; Ayas, E.; Öveçoğlu, M.L.; Turan, S. Fabrication of in situ Ni (W)-WC nano composites via mechanical alloying and spark plasma sintering. J. Alloy. Compd. 2012, 542, 97-104. [CrossRef]

29. Tingaud, D.; Sadat, T.; Dirras, G. Nickel-tungsten composite-like microstructures processed by spark plasma sintering for structural applications. In Spark Plasma Sintering of Materials; Cavaliere, P., Ed.; Springer: Cham, Switzerland, 2019 ; pp. 605-634.

30. Bokhonov, B.B.; Ukhina, A.V.; Dudina, D.V.; Anisimov, A.G.; Mali, V.I.; Batraev, I.S. Carbon uptake during spark plasma sintering: Investigation through the analysis of the carbide "footprint" in a Ni-W alloy. RSC Adv. 2015, 5, 80228-80237. [CrossRef]

31. Genç, A.; Kaya, P.; Ayas, E.; Öveçoğlu, M.L.; Turan, S. Microstructural evolution of mechanically alloyed and spark plasma sintered Ni-W alloy matrix composites. J. Alloys Compds. 2013, 571, 159-167. [CrossRef]

32. Sangeetha, S.; Kalaignan, G.P. Tribological and electrochemical corrosion behavior of Ni-W/BN (hexagonal) nano-composite coatings. Ceram. Int. 2015, 41, 10415-10424. [CrossRef]

33. Kirakosyan, H. Cu-Mo nanocomposite preparation by combining solution combustion synthesis and self-propagating hightemperature synthesis. J. Nano-Met. Chem. 2021; submitted.

34. Minasyan, T.; Kirakosyan, H.; Aydinyan, S.; Liu, L.; Kharatyan, S.; Hussainova, I. Mo-Cu pseudoalloys by combustion synthesis and spark plasma sintering. J. Mater. Sci. 2018, 53, 16598-16608. [CrossRef] 
35. Shkodich, N.F.; Rogachev, A.S.; Mukasyan, A.S.; Moskovskikh, D.O.; Kuskov, K.V.; Schukin, A.S.; Khomenko, N.Y. Preparation of copper-molybdenum nanocrystalline pseudoalloys using a combination of mechanical activation and spark plasma sintering techniques. Russ. J. Phys. Chem. B 2017, 11, 173-179. [CrossRef]

36. Benavides, P.A.; Soto, B.; Palma, R.H. Liquid phase sintering of mechanically alloyed Mo-Cu powders. Mater. Sci. Eng. A 2017, 701, 237-244. [CrossRef]

37. Yan, A.; Wang, Z.; Yang, T.; Wang, Y.; Ma, Z. Microstructure, thermal physical property and surface morphology of W-Cu composite fabricated via selective laser melting. Mater. Design. 2016, 109, 79-87. [CrossRef]

38. Nikitin, P.Y.; Zhukov, I.A.; Matveev, A.E.; Sokolov, S.D.; Boldin, M.S.; Vorozhtsov, A.B. AlMgB $14-\mathrm{TiB}_{2}$ composite materials obtained by self-propagating high-temperature synthesis and spark plasma sintering. Ceram. Int. 2020, 46, 22733-22737. [CrossRef]

39. Kevorkijan, V.; Škapin, S.D.; Suvorov, D. Synthesis and characterisation of ultra-hard and lightweight AlMgB14-xTiB2 composites for wear-resistance and ballistic protection. Metall. Mater. Eng. 2015, 21, 45-56. [CrossRef]

40. Elsayed, A.; Li, W.; El Kady, O.A.; Daoush, W.M.; Olevsky, E.A.; German, R.M. Experimental investigations on the synthesis of W-Cu nanocomposite through spark plasma sintering. J. Alloy. Compd. 2015, 639, 373-380. [CrossRef]

41. Marquis FD, S.; Mahajan, A.; Mamalis, A.G. Shock synthesis and densification of tungsten based heavy alloys. J. Mater. Process. Technol. 2005, 161, 113-120. [CrossRef]

42. Shchukin, A.S.; Scherbakov, A.V.; Sytschev, A.E.; Shcherbakov, V.A. Synthesis of composite based W-Ni-AL system by the electro-thermal explosion under pressure. Lett. Mater. 2018, 8, 274-277. [CrossRef] 